\title{
Nonlinear Analysis and Intelligent Control of Integrated Vehicle Dynamics
}

\author{
C. Huang, L. Chen, H. B. Jiang, C. C. Yuan, and T. Xia \\ School of Automobile and Traffic Engineering, Jiangsu University, Zhenjiang 212013, China \\ Correspondence should be addressed to L. Chen; chenlong@163.com
}

Received 24 September 2013; Revised 2 December 2013; Accepted 2 December 2013; Published 21 January 2014

Academic Editor: Hui Zhang

Copyright (c) 2014 C. Huang et al. This is an open access article distributed under the Creative Commons Attribution License, which permits unrestricted use, distribution, and reproduction in any medium, provided the original work is properly cited.

\begin{abstract}
With increasing and more stringent requirements for advanced vehicle integration, including vehicle dynamics and control, traditional control and optimization strategies may not qualify for many applications. This is because, among other factors, they do not consider the nonlinear characteristics of practical systems. Moreover, the vehicle wheel model has some inadequacies regarding the sideslip angle, road adhesion coefficient, vertical load, and velocity. In this paper, an adaptive neural wheel network is introduced, and the interaction between the lateral and vertical dynamics of the vehicle is analyzed. By means of nonlinear analyses such as the use of a bifurcation diagram and the Lyapunov exponent, the vehicle is shown to exhibit complicated motions with increasing forward speed. Furthermore, electric power steering (EPS) and active suspension system (ASS), which are based on intelligent control, are used to reduce the nonlinear effect, and a negotiation algorithm is designed to manage the interdependences and conflicts among handling stability, driving smoothness, and safety. Further, a rapid control prototype was built using the hardwarein-the-loop simulation platform dSPACE and used to conduct a real vehicle test. The results of the test were consistent with those of the simulation, thereby validating the proposed control.
\end{abstract}

\section{Introduction}

When a car is travelling at a high speed, a slight variation of the steering could result in a crash. Moreover, steering instability is primarily caused by the lateral force acting on the steering wheels, which is particularly affected by the sideslip angle [1]. When a vehicle navigates a large radius curve, the change in the sideslip angle is small and linearly related to the change in the lateral force. However, for high lateral accelerations, the wheel characteristic is nonlinear and the lateral force varies nonlinearly, thereby reducing the steering stability [2]. Under these complex conditions and the accompanying uncertainties, there are variations in the vertical load and lateral force acting on the wheel, as well as the longitudinal force of the vehicle. It is therefore necessary to develop an effective nonlinear model and employ more accurate processes such as the use of a neural network model and the sliding mode to achieve control requirements [3-5].

Currently, vehicle dynamics is mostly studied by means of nonlinear dynamics. For example, Wu and Sheng [6] established the phase plane of the sideslip angle and the rate at which it changes, which afforded a better method for the quantitative determination of the stability region. However, the method is limited by the simplified wheel model and cannot be theoretically used to determine the state and analyze the trend of the vehicle outside the stable area. Inagaki et al. [7] also studied the phase plane of the turning kinetic energy and forward kinetic energy and proposed a method for interpreting experimental observations and the results of quantitative analyses. However, the application of his method is also limited.

Shi et al. [8] established the potential energy function for the major parameters of a vehicle such as the sideslip angle of the wheel, steering wheel angle, and vehicle speed. In addition, he conducted qualitative and quantitative analyses to determine the steering stability region of a vehicle. Yang et al. [9] used the nonlinear dynamical center manifold theory to simplify a high-dimensional system to a one-dimensional center manifold system and theoretically analyzed the phenomenon of bifurcated limit cycles. He pointed out that saddle node bifurcation occurs with increasing speed and front wheel angle. 
Liu et al. [10] developed a nonlinear steering model of a front wheel drive vehicle, analyzed the Hopf bifurcation of the system, and confirmed that if the front wheel is periodically perturbed, chaotic motion would be produced in the system. Chang [11] created the bifurcation diagram of steer-by-wire vehicles for certain parameter ranges and used it to obtain the periodic and chaotic motions of the system. He proposed a chaotic feedback controller for steering the vehicle.

Ono et al. [12] analytically showed that the heading angle of a vehicle would be unstable if the heading speed exceeds a critical value. Beyond the critical speed, the vehicle may spin and possibly topple. Furthermore, Chang and Lin [13] used the bifurcation Lyapunov exponent to analyze complicated motions and offered detailed explanations of the topology change that occurs in the solutions of the mathematical model of a lateral system. A feedback controller of a linear lateral system has also been proposed and implemented in the steering system to enable the escape of a vehicle from the unstable domain, thereby preventing spinning and improving safety [14].

The steering and suspension are two important subsystems of the chassis of a vehicle, and both directly affect the overall vehicle performance, including handling stability, driving smoothness, and safety. The two systems are coupled and interact with each other. The suspension causes significant variations in the vertical force acting on the wheel, whereas the steering affects the lateral force, which in turn affects the overall lateral dynamics [15].

Studies have been conducted on the integrated control of electric power steering (EPS) and active suspension system (ASS) for complex nonlinear time-varying vehicle dynamics. The lateral and vertical dynamics of the vehicle were evaluated using different indexes, control strategies, and wheel dynamics. According to the linear superposition principle, if the lateral and vertical dynamics are separately controlled, the determined comprehensive properties would not be accurate. Over the past few years, diverse intelligent control strategies for integrated control have been proposed. March and Shim [16] developed an integrated control system for active front wheel steering and normal force control and used fuzzy logic to improve the vehicle handling. Yoshimura and Emoto [17] also used fuzzy logic and skyhook dampers to develop a steering and suspension system of a half car model subjected to irregular excitation by the surface of the road. Other techniques have been applied to the design of vehicle chassis control, such as sliding mode control and adaptive control [18-20]. More recently, the $H_{\infty}$ approach was used to produce promising designs of a vehicle chassis controller [21-25].

Chen et al. [26] developed a full car dynamic model that integrates EPS and ASS and used it to design a random suboptimal control strategy based on output feedback for integrated EPS and ASS control. Wang et al. [27] determined the structural parameters and used them to obtain the controller parameters by means of a simulated annealing algorithm. Furthermore, for simultaneous optimization, the major mechanical parameters of the EPS and ASS and some of the controller parameters were used as design variables, and the comprehensive dynamic performance of the automobile was selected as the target function. An EPS,
ASS, and rule-based central controller that supervised and coordinated the subsystems were designed based on the coupling relationships between the steering and suspension systems.

In the present study, a fuzzy control method was used to reduce the nonlinear effect, and a coordination mechanism was introduced to manage the interdependences and conflicts among handling stability, driving smoothness, and safety. Moreover, computer simulations were used to validate the bifurcation and chaotic motions implied by the integrated nonlinear differential equations that describe the vehicle dynamics. Finally, to conduct a real vehicle test, a rapid control prototype was built using the hardware-in-the-loop simulation platform dSPACE. The results of the test were consistent with those of the simulation, thereby validating the proposed control.

\section{Integrated Vehicle Dynamics}

2.1. Vehicle Model. To develop the vehicle dynamics model based on the steering working condition, the effect of the ground tangential force on the cornering properties of the wheel and the aerodynamics were ignored, as shown in Figure 1.

During the steering process of the vehicle, the effect of the roll angle and yaw velocity on changes in the sideslip angle cannot be ignored. The equations of motion of the vehicle were therefore derived by taking the effect of the roll angle into consideration and are as follows:

lateral movement of the vehicle:

$$
m v(\dot{\beta}+\gamma)-m_{s} h_{s} \ddot{\phi}=S_{1}+S_{2}+S_{3}+S_{4},
$$

yaw movement of the vehicle:

$$
I_{\gamma} \dot{\gamma}=l_{f}\left(S_{1}+S_{2}\right)-l_{r}\left(S_{3}+S_{4}\right)
$$

vertical movement of the vehicle:

$$
m_{s} \ddot{z}_{2}=F_{21}+F_{22}+F_{23}+F_{24}
$$

pitching movement of the vehicle:

$$
I_{\theta} \dot{\theta}=l_{r}\left(F_{21}+F_{22}\right)-l_{f}\left(F_{23}+F_{24}\right),
$$

roll movement of the vehicle:

$$
I_{\phi} \ddot{\phi}=m_{s} v(\dot{\beta}+\gamma) h_{s}+m_{s} g h_{s} \phi+\left(F_{21}+F_{23}-F_{22}-F_{24}\right) d \text {, }
$$

vertical movement of the unsuspended mass:

$$
m_{l i} \ddot{z}_{l i}=k_{l i}\left(z_{o i}-z_{l i}\right)-F_{2 i}, \quad(i=1,2,3,4) .
$$




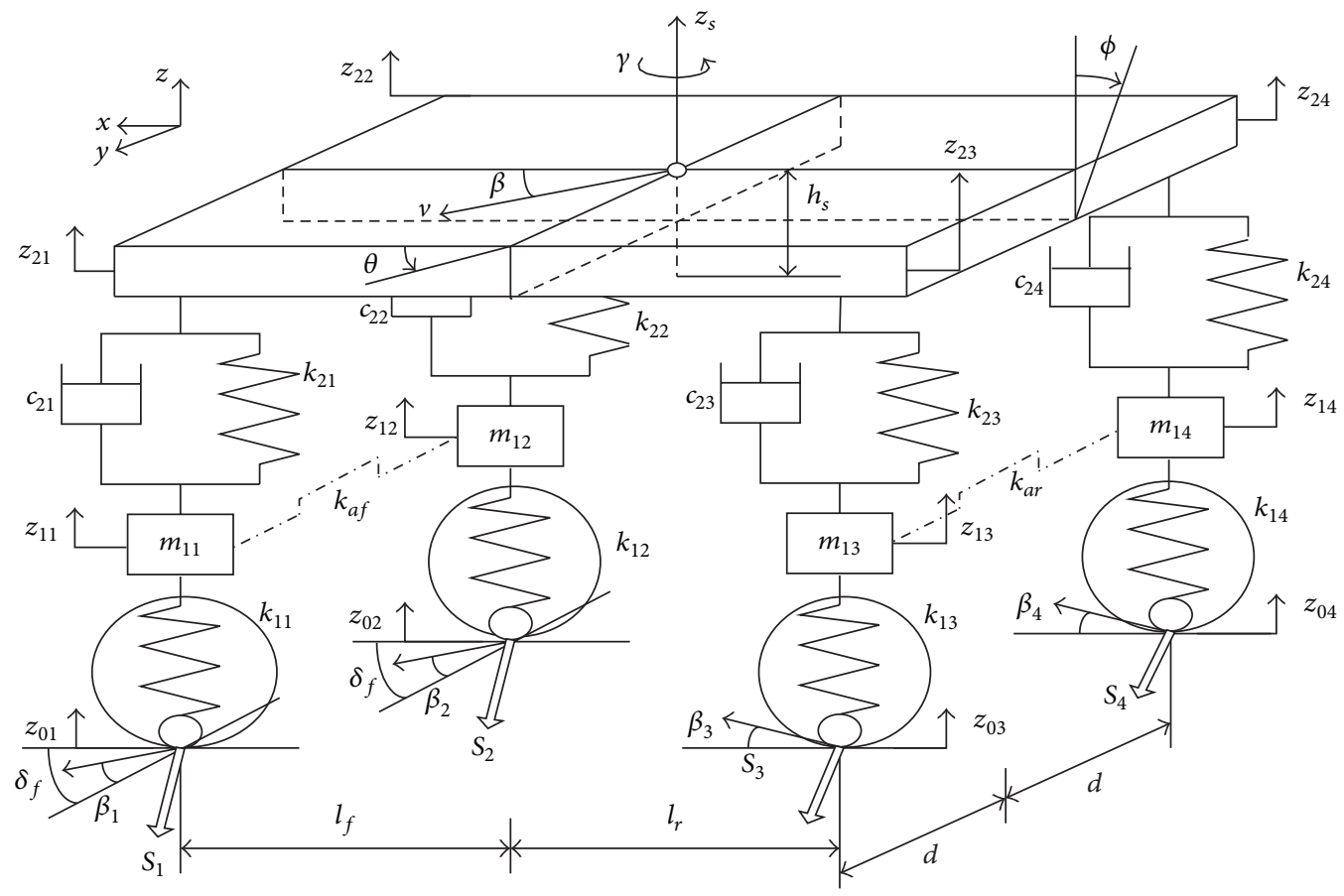

FIgURE 1: Vehicle dynamics model.

Taking into consideration the effect of the stabilizer bar on the inclination angle of the vehicle body, the resultant force of the suspension is given by the following:

$$
\begin{aligned}
& F_{21}=k_{21}\left(z_{11}-z_{21}\right)+c_{21}\left(\dot{z}_{11}-\dot{z}_{21}\right)-\frac{k_{a f}}{2 d}\left(\phi-\frac{z_{11}-z_{12}}{2 d}\right), \\
& F_{22}=k_{22}\left(z_{12}-z_{22}\right)+c_{22}\left(\dot{z}_{12}-\dot{z}_{22}\right)-\frac{k_{a f}}{2 d}\left(\phi-\frac{z_{11}-z_{12}}{2 d}\right), \\
& F_{23}=k_{23}\left(z_{13}-z_{23}\right)+c_{23}\left(\dot{z}_{13}-\dot{z}_{23}\right)-\frac{k_{a r}}{2 d}\left(\phi-\frac{z_{13}-z_{14}}{2 d}\right), \\
& F_{24}=k_{24}\left(z_{14}-z_{24}\right)+c_{24}\left(\dot{z}_{14}-\dot{z}_{24}\right)-\frac{k_{a r}}{2 d}\left(\phi-\frac{z_{13}-z_{14}}{2 d}\right) .
\end{aligned}
$$

When the pitch angle $\theta$ and inclination angle $\phi$ are in the minor range, the following approximations can be obtained:

$$
\begin{aligned}
& z_{21}=z_{s}-l_{f} \theta-d \phi, \\
& z_{22}=z_{s}-l_{f} \theta+d \phi, \\
& z_{23}=z_{s}+l_{r} \theta+d \phi, \\
& z_{24}=z_{s}+l_{f} \theta-d \phi .
\end{aligned}
$$

2.2. Wheel Model. When a real vehicle is traveling on a nonflat road, the effect of the road on the wheel varies, which makes it necessary to obtain a dynamic model that is adaptable to environmental changes. The adaptive neural network (ANN) is more appropriate and is as follows:

$$
T=\left\{F_{y}\right\}=\mathrm{NN}\left\{\left[\begin{array}{c}
\alpha \\
P \\
v \\
F_{z} \\
F_{y(n-1)}
\end{array}\right]\right\} .
$$

ANN includes the input layer, hidden layer, and output layer. The input layer contains five variables, namely, the sideslip angle of the wheel $\alpha$, the wheel pressure $P$, the vertical load $F_{z}$, the velocity $v$, and the lateral force of the previous step $F_{y(n-1)}$. The hidden layer is composed of several nonlinear transfer functions, whereas the output layer is composed of a single variable, which is the lateral force acting on the wheel, $F_{y}$.

The input of the neuron in the hidden layer of the network is given by

$$
\theta_{j}(k)=\sum_{i=1}^{m} w_{i j} p_{i}(k) ; \quad j=1,2, \ldots, 8 ; m=5 .
$$

The relationship between the input and output of the hidden layer is given by the following sigmoid function, which is an expression of the output of the neuron in the hidden layer:

$$
\xi_{j}(k)=f\left[\theta_{j}(k)\right] ; \quad j=1,2, \ldots, 8 .
$$




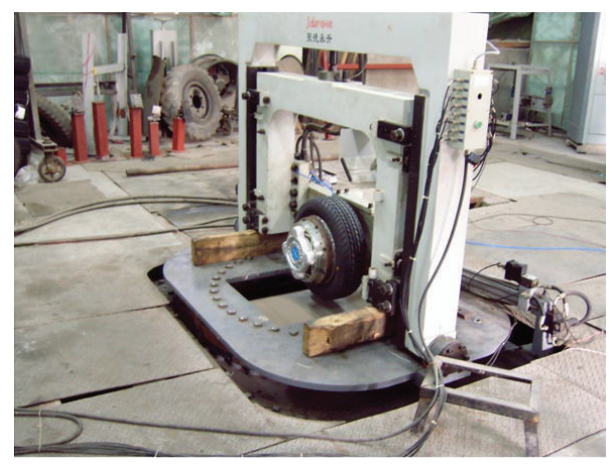

Figure 2: Analytical tire contact system.

The output layer consists of one neuron, the input function of which is as follows:

$$
\varsigma_{l}(k)=\sum_{j=1}^{n} v_{j l} \xi_{j}(k) ; \quad l=1 ; n=8 .
$$

The relationship between the input and output of the output layer is given by the following sigmoid function:

$$
I_{l}=f\left[\varsigma_{l}(k)\right] ; \quad l=1 .
$$

Let us assume that the inclination angles of the left- and right-side wheels are equal and that the inclination angles of the front and rear wheels can be expressed as

$$
\begin{gathered}
\alpha_{1}=\alpha_{2}=\delta_{f}-\beta-\frac{l_{f} \gamma}{v}+E_{f} \phi, \\
\alpha_{3}=\alpha_{4}=\frac{l_{r} \gamma}{v}-\beta+E_{r} \phi .
\end{gathered}
$$

For our experiments, we used a 165/65R13 Radial Tyre (Hankooktire). The equipments used for the experiments included a Vehicle Tyre Road Rotating Test Stand (Figure 2) and a T-8050 Tyre Road Contacting Pressure Analysis System (US Tekscan Company).

Based on the characteristics of the Magic formula model, a comparative analysis of the fitting performances of the adaptive and Magic formula models was conducted using experimental tire data for different loads and with the assumption of steady working conditions, namely, a wheel speed of $20 \mathrm{~km} / \mathrm{h}$ and inflation pressure of $250 \mathrm{kPa}$ (Figure 3 ). As shown in the figure, the adaptive model produces a better fit of the experimental data. In the case of the Magic formula, because the trigonometric function is used as the base function, the fitting curve is only close to and crosses the experimental data. Moreover, there are distortions in the approximation of the lateral force.

\section{Nonlinear Analysis of Lateral and Vertical Vehicle Dynamics}

3.1. Coupled Mechanism. Figure 4 is a diagram of the interaction between the suspension and steering systems. The double

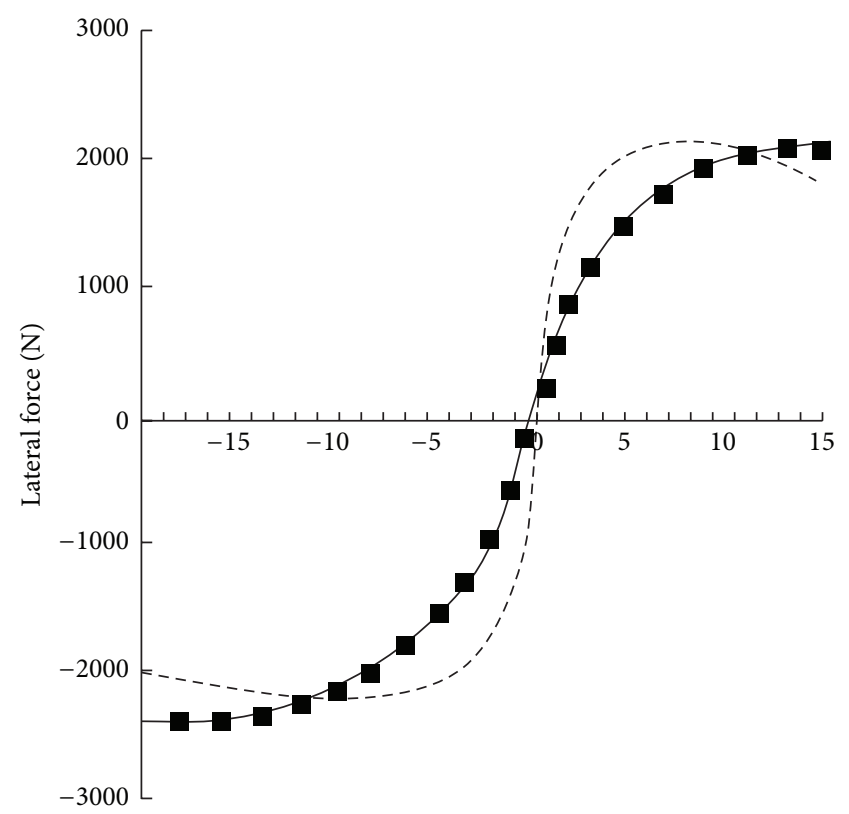

Slip angel $\left({ }^{\circ}\right)$

$$
\begin{array}{ll}
\square & \text { Test } \\
- & \text { ANN } \\
--- & \text { Magic }
\end{array}
$$

Figure 3: Model fitting.

lines in the figure indicate the basic and direct actions; the solid lines indicate the indirect effect of its functions; and the dashed lines indicate the constraints. When an increase in the gain of one of either the suspension or steering system is used to improve the performance of the system, the indirect effect on the performance of the other system is also significantly increased. For example, if the roll stiffness of the suspension is increased, the roll angle would decrease, resulting in a weakening of the under steer characteristics and an increase in the yaw velocity gain, which in turn deteriorates the yaw response characteristics.

It can be seen from (1)-(6) that the steering of a vehicle affects the roll of the body by laterally accelerating it, which in turn affects the motion of the suspension subsystem. The vertical force acting on the wheel changes significantly, which affects the vertical motion. The wheel model (see (9)) shows that this causes additional changes in the lateral force acting on the wheel, which in turn affects the overall lateral dynamics. This indicates that there are intercoupling and interaction between the steering and suspension systems of the vehicle.

3.2. Nonlinear Computation. An analytical solution of the nonlinear dynamic system of a coupled neural network is extremely cumbersome, which makes its actual application difficult. It is thus necessary to obtain an approximate solution by a numerical method, that is, to convert the differential differential equation to a differential equation. In this study, Matlab/Simulink was used to develop a simulation model, the calculation flow of which is shown in Figure 5. The model 


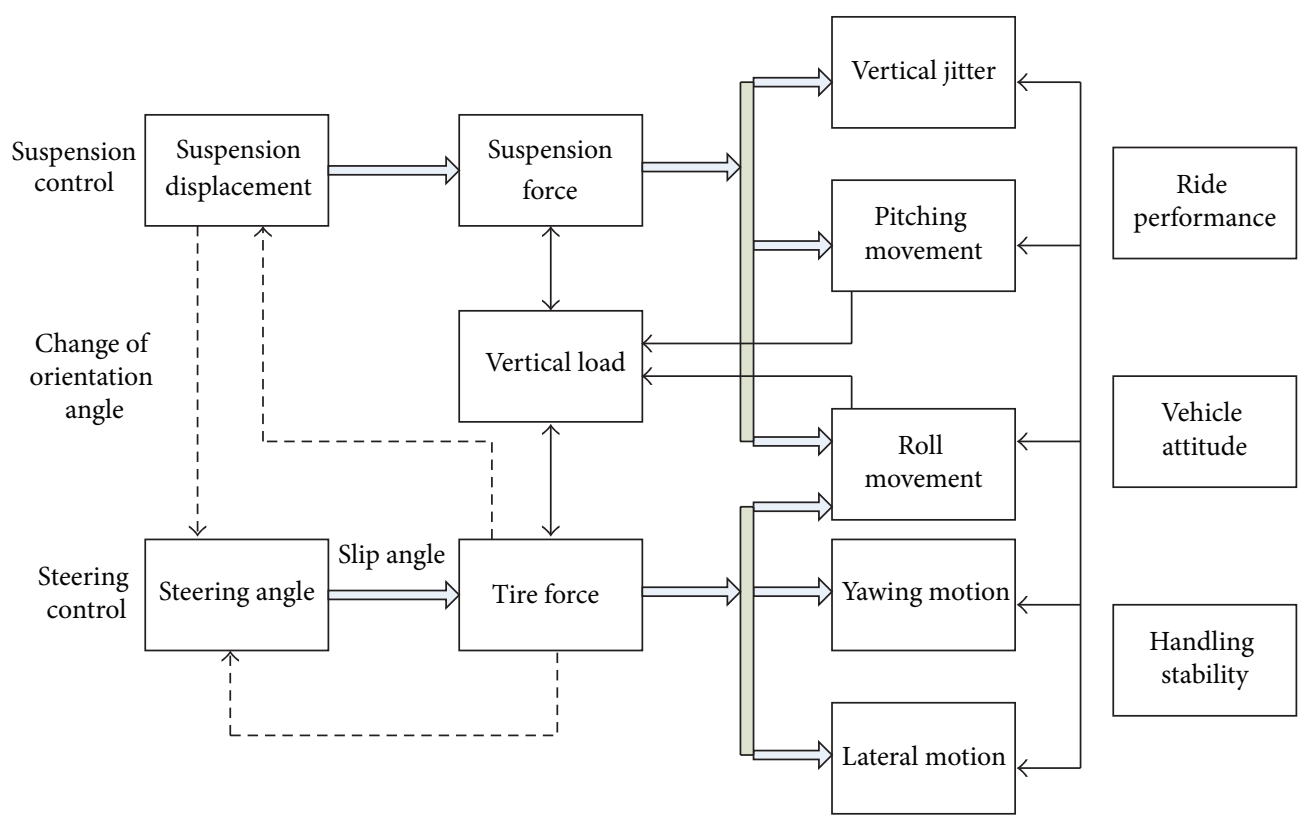

FIGURE 4: Interaction between the suspension and steering systems.

TABLE 1: Vehicle parameters.

\begin{tabular}{lc}
\hline Parameter & Value \\
\hline Kerb weight/kg & 900 \\
Maximum total weight/kg & 1330 \\
Unsprung mass (front/rear)/kg & $35 / 33$ \\
Front axle weight (empty/full)/kg & $540 / 640$ \\
Wheel base/mm & 2335 \\
Front axle-centred distance/mm & 955 \\
Rear axle-centred distance/mm & 1380 \\
Front/rear wheel tread/mm & $1360 / 1355$ \\
Vehicle body & $3400 / 1575 / 1670$ \\
length/width/height/mm & $165 / 65 \mathrm{R} 13$ \\
Wheel model/mm &
\end{tabular}

parameters were chosen with reference to those of a real vehicle and are given in Table 1.

The maximum Lyapunov exponent method and the phase plane method are the major methods used to examine the nonlinear system in this paper. In mathematics, the Lyapunov exponent characterizes the rate of separation of infinitesimally close trajectories. Quantitatively, the rate at which two trajectories separated by $\delta Z_{0}$ in a phase space diverge (provided the divergence can be treated using its linearized approximation) is given by

$$
|\delta Z(t)| \approx e^{\lambda t}\left|\delta Z_{0}\right| .
$$

The rate of separation may be different for different orientations of the initial separation vector. Thus, there is a spectrum of Lyapunov exponents, the number of which is equal to the dimensionality of the phase space. The largest exponent is commonly referred to as the maximal Lyapunov

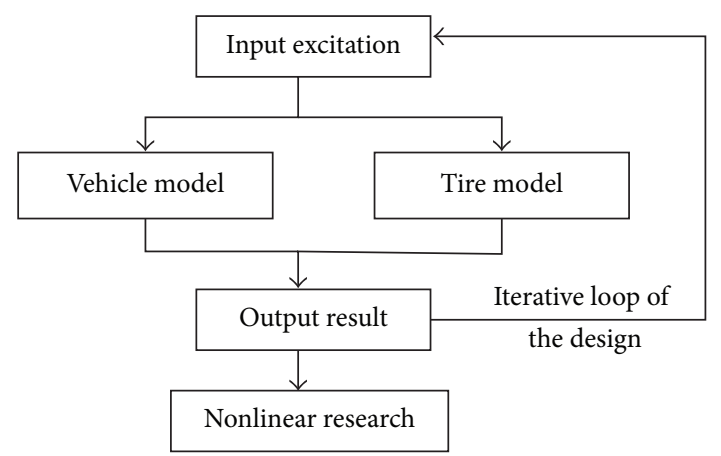

FIgURE 5: Calculation flowchart.

exponent (MLE) because it determines the predictability for a dynamic system. A positive MLE is usually considered as an indication that the system is chaotic (provided some other conditions are met, e.g., the compactness of the phase space). It should be noted that an arbitrary initial separation vector would typically have a component in the direction of the MLE, and the exponential growth rate would obliterate the effect of the other exponents over time.

The maximal Lyapunov exponent is defined as follows:

$$
\lambda=\lim _{t \rightarrow \infty} \lim _{\delta Z_{0} \rightarrow 0} \frac{1}{t} \ln \frac{|\delta Z(t)|}{\left|\delta Z_{0}\right|} .
$$

The limit $\delta Z_{0}$ ensures the validity of the linear approximation at any time.

When computing the maximal Lyapunov exponent, the time series should be reconstructed to determine the closest point $V_{j^{\prime}}$ for every point $V_{j}$. 
The separation interval is defined as follows:

$$
\omega=\frac{\max \left(\tau_{i}\right)}{\Delta t} ; \quad i=1,2, \ldots, M .
$$

It is assume that $d_{j}(0)$ is the distance between $V_{j}$ and its closest point $V_{j^{\prime}}$; that is,

$$
d_{j}(0)=\left\|V_{j}-V_{j^{\prime}}\right\|, \quad\left|j-j^{\prime}\right|>\omega .
$$

For every point $V_{j}$ in the phase space, the distance to its closest point after the forward evolution in the $i$ th step is calculated using

$$
d_{j}(i)=\left\|V_{j+1}-V_{j+i^{\prime}}\right\|
$$

where $i=J_{0}, J_{0+1}, \ldots, N$.

Assuming that the closest point of $V_{j}$ diverges at the rate of the Lyapunov exponent, namely, $d_{j}(i)=d_{j}(0) \times e^{\lambda(i \Delta t)}$, the logarithm on both sides is used to obtain $\ln d_{j}(i)=\ln d_{j}(0)+$ $\lambda(i \Delta t)$. The least square method is then used to fit the curve of $\ln d_{j}(i)$ relative to $i \Delta t$ to obtain the maximal Lyapunov exponent $\lambda_{1}$ :

$$
\lambda_{1}=\frac{[i \times y(i)]}{\sum i^{2}},
$$

where $y(i)=\left(\sum_{j=1}^{p} \ln d_{j}(i)\right) /(p \Delta t)$ and $p$ is the number of nonzero $d_{j}(i)$.

A phase plane is a visual display of certain characteristics of certain types of differential equations. However, a coordinate plane is a plane whose axes represent two state variables such as $(x, y),(q, p)$, or any other pair of variables. It is a twodimensional case of the general $n$-dimensional phase space and can be used to determine the stability or otherwise of the dynamics.

3.3. Analysis of Results. The yaw angle rate $\gamma$ of the chassis is the riding and visual evaluation index of the driver during steering. It is therefore necessary to study the dynamic behavior of $\gamma$ to explain a variety of phenomena and evaluate the stability and control of the steering process.

In the bifurcation diagram (Figure 6), as the velocity $v$ increases, $\gamma$ initially maintains a single stable period. When $v$ reaches $15 \mathrm{~km} / \mathrm{h}, \gamma$ suddenly becomes chaotic. As $v$ further increases to $45 \mathrm{~km} / \mathrm{h}, \gamma$ suddenly changes to a period- 4 motion. After another short period of stability, $\gamma$ enters the chaotic state again and finally converges to a period-1 motion with further increase in $v$.

Figure 7 shows that when $v$ increases from zero, $\lambda$ begins at a negative value and continuously fluctuates as the absolute value of $v$ increases. $\lambda$ is zero when $v=15 \mathrm{~km} / \mathrm{h}$ and subsequently becomes positive, which indicates that the system becomes chaotic. This shift corresponds to the change of $\gamma$ from a period-1 motion to the chaotic state (Figure 6). As $v$ increases from 15 to $50 \mathrm{~km} / \mathrm{h}, \lambda$ fluctuates, alternating increasing from and decreasing back to zero. When $v$ is 25 or $40 \mathrm{~km} / \mathrm{h}, \lambda$ assumes a local maximum value. These local maximums correspond to regions in which the attractors are

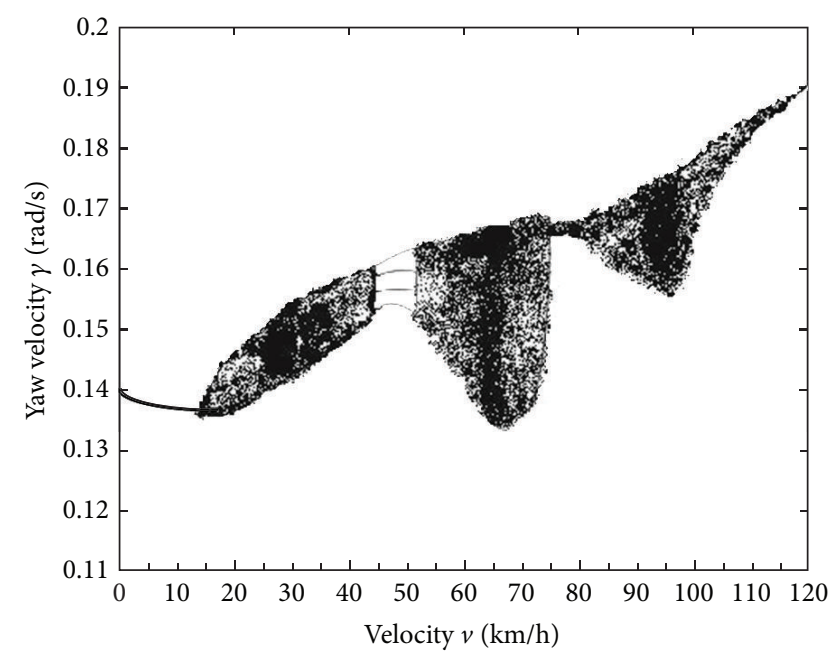

FiguRE 6: Bifurcation diagram.

TABLE 2: Description of control mode.

\begin{tabular}{lcc}
\hline Identification & Rule & Working condition \\
\hline 1 & $c_{2} \wedge c_{3} \wedge c_{5}$ & Assist \\
2 & $c_{1} \wedge c_{5}$ & Damping \\
3 & $c_{2} \wedge c_{6}$ & Aligning \\
\hline
\end{tabular}

densely distributed in Figure 6. As $v$ approaches $50 \mathrm{~km} / \mathrm{h}, \lambda$ changes rapidly and assumes a global minimum value. In the bifurcation diagram in Figure 6, the attractors maintain the four-period stable state, after which the chaotic state is reentered. When $v=65 \mathrm{~km} / \mathrm{h}, \lambda$ assumes another maximum value, which is the global maximum and corresponds to a narrow strip of densely distributed chaotic attractors in Figure 6 . Subsequently, $\lambda$ gradually decreases and the chaotic attractors correspondingly decrease in density and become increasingly narrow in scope. The attractors are narrowest at $v=80 \mathrm{~km} / \mathrm{h}$, at which point $\lambda$ is zero, after which it increases again. When $v=95 \mathrm{~km} / \mathrm{h}, \lambda$ assumes another local maximum. However, when $v$ exceeds $95 \mathrm{~km} / \mathrm{h}, \lambda$ continuously decreases. The Lyapunov exponent tends to negative infinity with continuous thinning of the chaotic attractors and convergence to a stable fixed point in the bifurcation diagram (Figure 6).

\section{Intelligent Control for Chaotic State}

4.1. EPS Based on Fuzzy Control. The input signals and system state are specified by $S=\left\{s_{1}, s_{2}, s_{3}, s_{4}\right\}$, where $s_{1}$ is the steering wheel torque, $s_{2}$ is the velocity, $s_{3}$ is the wheel steering angle, and $s_{4}$ is the motor current. The environment is categorized into three working conditions, namely, assist, damping, and aligning (see Tables 2 and 3 for the criteria for determining the working condition).

The schedule of the fuzzy rules is based on the working condition. In the assist condition, a seamless velocity assist mode is employed using a velocity range of $0-200 \mathrm{~km} / \mathrm{h}$ and intervals of $20 \mathrm{~km} / \mathrm{h}$. For each velocity, the assist provided 
TABLE 3: Conditions of EPS hybrid control system.

\begin{tabular}{lc}
\hline Identification & Logical expression \\
\hline$c_{1}$ & $T_{d}<T_{d, 0}$ \\
$c_{2}$ & $\neg c_{1}$ \\
$c_{3}$ & $u_{\text {vehicle }}<u_{\text {vehicle,max }}$ \\
$c_{4}$ & $\neg c_{4}$ \\
$c_{5}$ & $\theta_{h} \dot{\theta}_{h}>0$ \\
$c_{6}$ & $\neg c_{5}$ \\
\hline
\end{tabular}

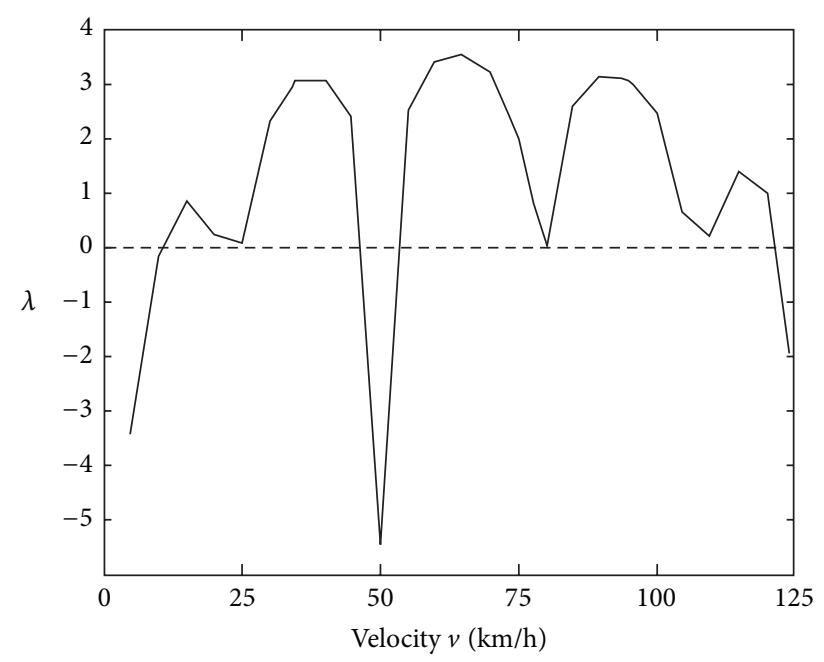

FIGURE 7: Lyapunov exponent diagram.

by the motor can be divided into three segments, which are as follows. When the steering wheel input torque is in the range of $0-1 \mathrm{Nm}$, there is a boosting dead zone and no assist is provided by the motor. When the input torque is in the range of $1-6 \mathrm{Nm}$, there is an assist zone. When the torque is beyond this range, there will be a $6 \mathrm{Nm}$ assist saturated zone. The four parameters used for designing linear assist are the steering wheel input torque $T_{d, 0}$ at the beginning of the assist, the maximum steering wheel input torque $T_{d \text {,max }}$, the motor current maximum value $I_{t, \max }$, and the coefficient $k(v)$. The characteristics of the designed linear assist and its function expressions are as shown in Figure 8:

$$
I_{t}= \begin{cases}0, & \left|T_{d}\right| \leq T_{d, 0} \\ k(v) f\left(T_{d}-T_{d, 0}\right), & T_{d, 0} \leq\left|T_{d}\right| \leq T_{d, \max }, \\ I_{t, \max }, & \left|T_{d}\right| \geq T_{d, \max } .\end{cases}
$$

Based on the requirements and objectives, the aligning condition is composed of two parts. One is the aligning control, the major function of which is the provision of necessary assist for easy steering of the wheel back to the central position. In this process, the aligning control functions as a PI adjuster for adjusting the target steering wheel position $\theta$ and the actual steering wheel variance $e_{h}$, outputting the control voltage and allowing the motor to bring the steering wheel back to the central position:

$$
V_{\mathrm{mrl}}=-\left(K_{p} e_{h}+K_{i} \int e_{h} \mathrm{dt}\right)
$$

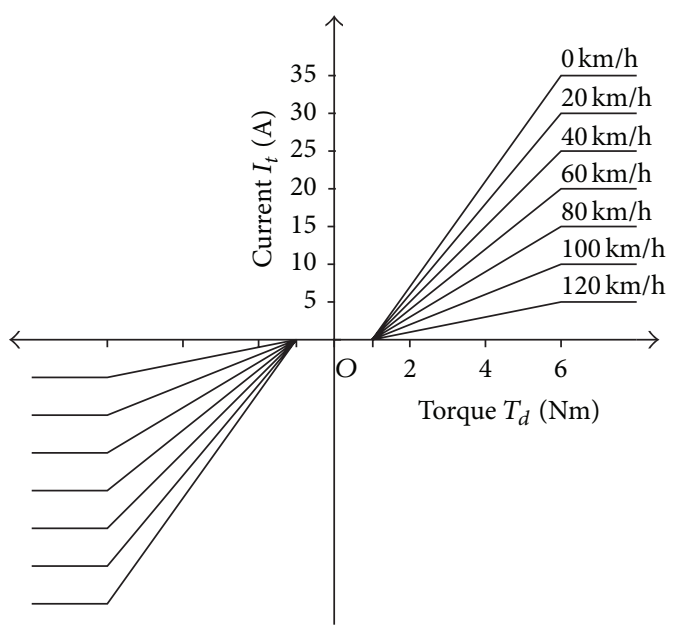

FIGURE 8: Characteristics of a linear assist.

The other part is damping control, the major function of which is to bring the vehicle back to the central position and avoid the shimmy events under the damping condition. During this process, a certain control voltage is generated based on the angular velocity of the aligning process, which produces a certain damping torque in the motor. The quicker the steering wheel spins, the higher the control voltage generated and the larger the damping torque is. Conversely, the slower the steering wheel spins, the smaller the damping torque is. The steering wheel alignment speed can therefore be adjusted by adjusting the damping coefficient:

$$
V_{\mathrm{mrh}}=-K_{d} \dot{e}_{h} .
$$

The alignment control and the damping control can be integrated in one PID returning control algorithm. Moreover, by adjusting the coefficient, alignments that produce different effects can be obtained as expressed by the following:

$$
V_{\mathrm{mr}}=-\left(K_{p} e_{h}+K_{i} \int e_{h} \mathrm{dt}+K_{d} \dot{e}_{h}\right) .
$$

In the damping condition, the operation status of the system is determined by the value of the deviation $\left|e_{d}\right|$, and timely adjustment is made to the structure of the controller. The controlling rules are as follows:

$$
\begin{aligned}
& \text { IF } e_{d}>+e_{d, \text { max }} \text { THEN } K_{d, \mathrm{PWM}, m}=+K_{d, \mathrm{PWM}, \max }, \\
& \text { IF } e_{d} \leq-e_{d, \text { max }} \text { THEN } K_{d, \mathrm{PWM}, m}=-K_{d, \mathrm{PWM}, \max } .
\end{aligned}
$$

The input variable $e$ and the rate of change of the deviation $e c$ are determined by computing the deviation between the actual current in the current booster motor and the target current, to carry out fuzzy query using the fuzzy rules and to query the fuzzy matrix table. The parameters $k_{p}, k_{i}$, and $k_{d}$ controlled by the PID are then adjusted for adaptation (see Table 4 and Figure 9).

4.2. ASS Based on Fuzzy Control. In the external state $P=$ $\left\{p_{1}, p_{2}, p_{3}, p_{4}, p_{5}\right\}, p_{1}$ is the vertical acceleration $\ddot{Z}_{s}, p_{2}$ is the 


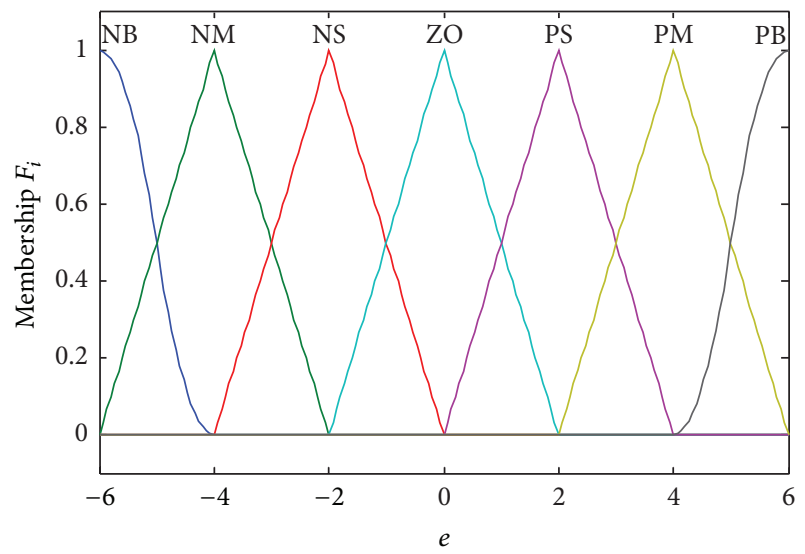

Figure 9: Membership function of variable $e$.

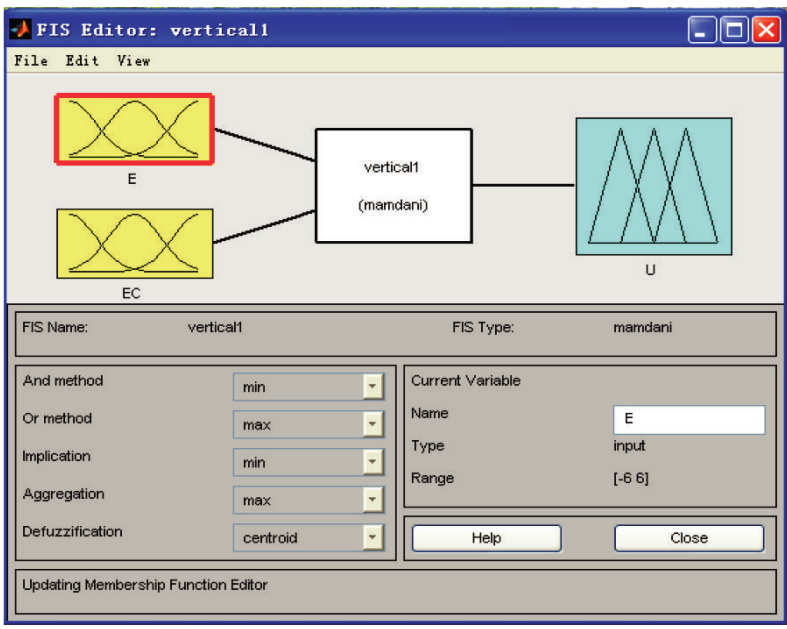

FIGURE 10: Fuzzy controller interface in Matlab/Simulink.

TABLE 4: Fuzzy rule table.

\begin{tabular}{lccccccc}
\hline$e c$ & NB & NM & NS & ZO & PS & PM & PB \\
\hline NB & PB & PB & PM & PM & PS & ZO & ZO \\
NM & PB & PB & PS & ZO & NS & ZO & NS \\
NS & PM & PM & PM & PS & ZO & NS & NS \\
ZO & PM & PM & PS & ZO & NS & NM & NM \\
PS & PS & PS & ZO & NS & NS & NM & NM \\
PM & PS & PS & ZO & NS & NM & NM & NB \\
PB & ZO & ZO & NM & NM & NM & NB & NB \\
\hline
\end{tabular}

pitching angular speed of the vehicle $\dot{\theta}, p_{3}$ is the vehicle body roll angular speed $\dot{\theta}, p_{4}$ is the suspension dynamic deflection $f_{d}$, and $p_{5}$ is the wheel vertical acceleration $\ddot{Z}_{t}$.

To rank the changing amplitudes of $p_{1}, p_{2}, p_{3}, p_{4}$, and $p_{5}$ based on their values and achieve selective control (using the belief rules) of $\ddot{Z}_{s}, \dot{\phi}, f_{d}$, and $\ddot{Z}_{t}$ by combining the operation condition of the wheel angel with the velocity signal, the

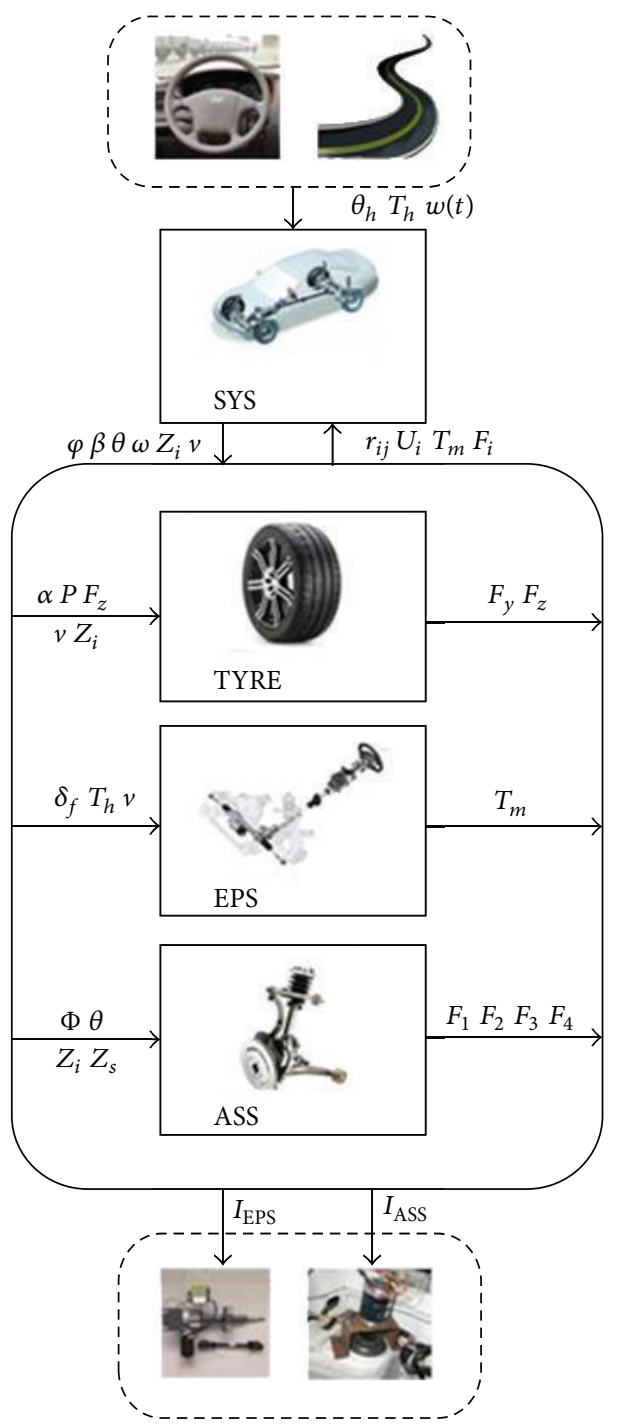

FIgURE 11: Schematic diagram.

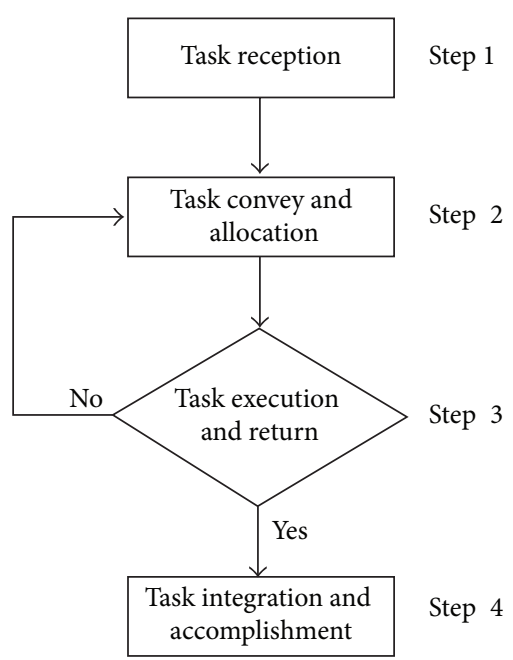

Figure 12: State flow of the controlling strategy. 


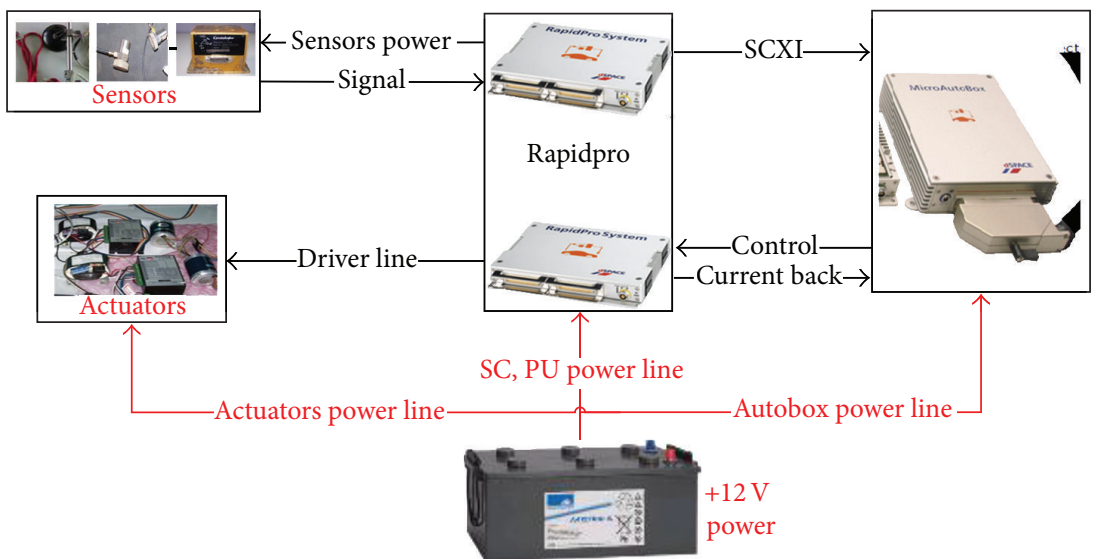

FIGURE 13: Rapid control system.

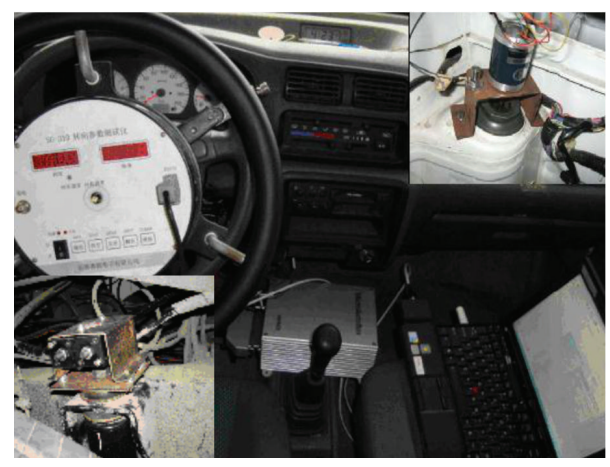

FIGURE 14: Entire control loop.

following control rules are used together with (24)-(25):

$$
\begin{aligned}
& \text { Steering } \rightarrow \dot{\theta} \cap \dot{\phi} \cap \ddot{Z}_{s} \rightarrow \text { "stability", } \\
& \text { Medium and low speed } \rightarrow \ddot{Z}_{s} \cap f_{d} \rightarrow \text { "comfort", } \\
& \text { High speed } \rightarrow \dot{\phi} \cap \ddot{Z}_{t} \cap \ddot{Z}_{s} \rightarrow \text { "safety". }
\end{aligned}
$$

The fuzzy logic system can be described as follows:

$$
\begin{aligned}
& \text { if } x_{1}(t)=F_{1 j}, \quad x_{2}(t)=F_{2 j}, \ldots, x_{n}(t)=F_{n j} \text {, } \\
& \text { then } y_{j}(t)=G_{j} \quad(j=1,2, \ldots, 4) .
\end{aligned}
$$

In this formula, $x=\left(x_{1}, x_{2}, \ldots, x_{n}\right)^{T}$ and $y$ are the language variables; $F_{i j}(i=1,2, \ldots, n)$ and $G_{j}$ are the fuzzy sets; and $l$ is the number of rules. The output is

$$
f(x)=\frac{\sum_{l=1}^{m} y_{l}\left[\prod_{i=1}^{n} \mu_{F_{i j}}(x)\right]}{\sum_{l=1}^{m}\left[\prod_{i=1}^{n} \mu_{F_{i j}}(x)\right]},
$$

where $\mu_{F_{i j}}$ is the membership function of the fuzzy set of $F_{i j}$ :

$$
F_{i}=\sum_{j=1}^{m}\left(\min f\left(x_{j}\right)\right), \quad i=1,2,3,4
$$

$$
\text { s.t. If "stability" } \rightarrow x_{1}=\dot{\theta}, x_{2}=\dot{\phi}, x_{3}=\ddot{Z}_{s} \text {, }
$$

$$
\begin{aligned}
& \text { If "comfort" } \rightarrow x_{1}=\ddot{Z}_{s}, x_{2}=f_{d}, \\
& \text { If "safety" } \rightarrow x_{1}=\dot{\phi}, x_{2}=\ddot{Z}_{t}, x_{3}=\ddot{Z}_{s} .
\end{aligned}
$$

The fuzzification and defuzzification processes of the fuzzy control of this study were designed using the fuzzy logic toolbox in MATLAB/Simulink (see Figure 10).

4.3. Negotiation Algorithm for Intelligent Control. Figure 11 shows a control strategy for vehicle integrated chassis control. Because it is difficult to directly determine the interrelations between EPS and ASS, the controller was designed using four parts as follows: TYRE, EPS-, ASS, and SYS. The inputs are the road noise $\mathrm{w}(\mathrm{t})$, steering wheel angle $\theta_{h}$, and steering wheel torque $T_{h}$, and the outputs are the controlled current $I_{\mathrm{ASS}}$ powered by ASS and the controlled current $I_{\mathrm{EPS}}$ powered by EPS.

The logical process of the negotiation algorithm is as follows (see Figure 12):

input: road noise $\mathrm{w}(\mathrm{t})$, steering wheel angle $\theta_{h}$, and steering wheel torque $T_{h}$,

output: the controlled current $I_{\text {ASs }}$ powered by ASS, and the controlled current $I_{\mathrm{EPS}}$ powered by assist motors.

Step 1 (task reception). Categorize the operation conditions into steering control, suspension control, and coordination control based on the external input $\mathrm{w}(\mathrm{t}), \theta_{h}$, and $T_{h}$. For steering control and suspension control, the operation conditions can be determined within the capacity limitations of the single EPS and ASS, which would initiate the corresponding agent and at the same time notify that the agent has been occupied by the operation conditions and should stop receiving new operation conditions until the completion and return of the current condition. However, if the current operation condition fails to accomplish the process by a single attempt, it means that it is beyond its capacity. The operation condition would thus be rejected and would return to the rank for allocation to others.

Step 2 (task convey and allocation). With the whole vehicle model, after obtaining signals $\beta, \omega, \theta, \varphi, Z_{i}$ for the vehicle 


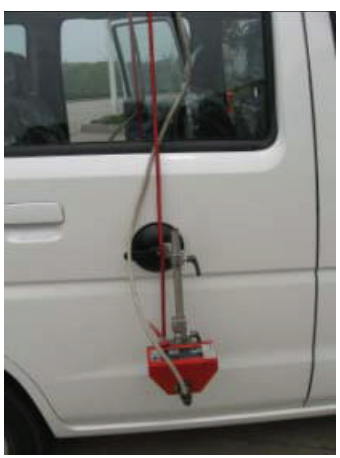

(a) Speed sensors installed on the vehicle

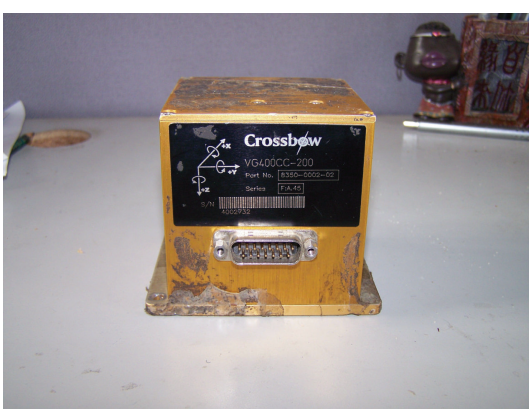

(c) Gyroscope

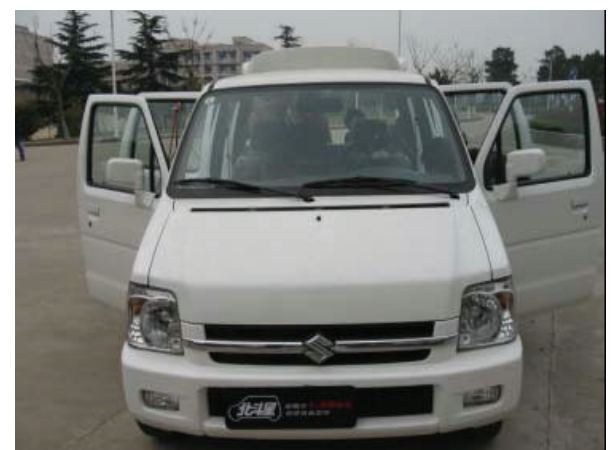

(b) Test car

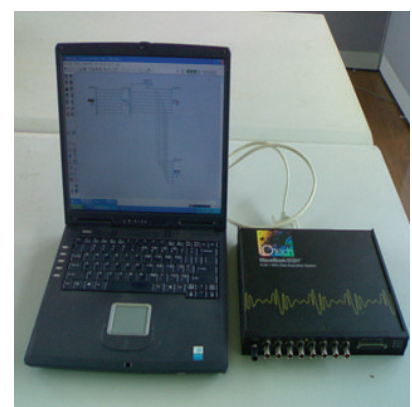

(d) Data acquisition box

FIGURE 15: Main parts of the test and control systems.

body and making reference to the values for the velocity $v$ and the rotation angle $\delta_{f}$ for the front wheels, the system would make a timely definition for employment and the proportion of the vague weights. Based on the planned working conditions allocation strategy, the target is subcategorized into several subtargets for the respective accomplishment.

Step 3 (task execution and return). After receiving orders for the subtargets, the EPS receives signals for the steering wheel torque $T_{h}$ and velocity $v$ and then uploads a set of solutions for the steering wheel assist and orientation. Regarding the ASS, after receiving the order for the subtargets, it receives the signals $\theta, \Phi, Z_{s}$, and $Z_{i}$ for the vehicle body and uploads a set of solutions for the orientation of $F_{i}$ powered by the suspension.

Step 4 (task integration and accomplishment). The controller coprocesses all the subsystems collected during the sequences of vague relational weights as follows:

input: the proposals for $a_{\mathrm{EPS}}$ and $a_{\mathrm{SAS}}$ at the negotiation of turn $j\left(x^{(j)}, y^{(j)}\right)$; utility value $V_{j-1}$,

output: the proposals for $a_{\mathrm{EPS}}$ and $a_{\mathrm{SAS}}$ at the negotiation of turn $j+1\left(x^{(j+1)}, y^{(j+1)}\right)$.

(1) Compute $V_{j}\left(x^{(j)}, y^{(j)}\right)$.

(2) If $V_{j}\left(x^{(j)}, y^{(j)}\right) \leq V_{j-1}\left(x^{(j-1)}, y^{(j-1)}\right)$, then the negotiation is a failure; if $V_{j}\left(x^{(j)}, y^{(j)}\right)>V_{j-1}\left(x^{(j-1)}, y^{(j-1)}\right)$, then the negotiation is a success and is followed by a return to the negotiation results $\left(x^{(j)}, y^{(j)}\right)$.
(3) Compute the concession Rs $=V_{j}\left(x^{(j)}, y^{(j)}\right)-$ $V_{j-1}\left(x^{(j-1)}, y^{(j-1)}\right) / \mathrm{N}$ to generate $V_{j+1}=V_{j}\left(x^{(j)}\right.$, $\left.y^{(j)}\right)-R s$, and return to $a_{\mathrm{EPS}}$ and $a_{\mathrm{SAS}}$ for a new proposal $\left(x^{(j+1)}, y^{(j+1)}\right)$.

(4) Output the proposal.

Using the above task integration, the return results for the entire operation condition can be obtained to output the controlled current $I_{\text {ASs }}$ powered by the suspension and the steering force-controlled current $I_{\mathrm{EPS}}$.

\section{Road Test and Result}

5.1. Test Device and System. The tests were performed using the control system shown in Figure 13. It comprises a rapid control module, an actuator system, and a sensor system. The SC unit is used for communication between the sensor system and the main controller unit, whereas the PU is used for communication between the actuators and the main controller unit. The 1401/1505/1507 MicroAutoBox is used as the main controller unit. In the actuator and dSPACE system, an input power of $12 \mathrm{~V}$ was obtained from the car battery. The vehicle state was determined using an arm position sensor, gyroscopes, a vehicle speed sensor, and a data acquiring box. The entire control loop shown in Figure 14 is closed by the driver. The main parts of the control and test systems are shown in Figure 15.

5.2. Road Test. To validate the control, a step input road and various S-shaped operation conditions were used to perform 


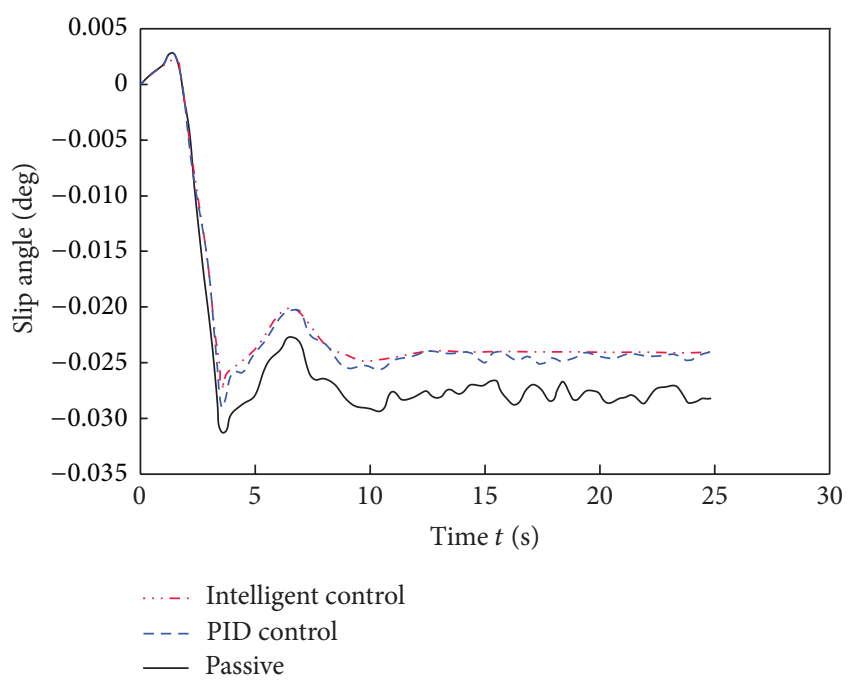

(a) Slip angle of vehicle body

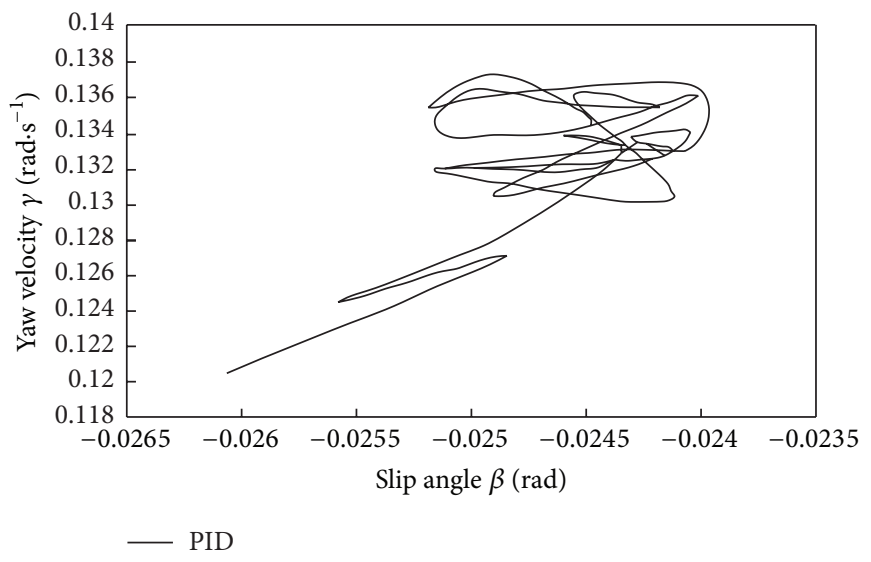

(c) Phase portrait without control

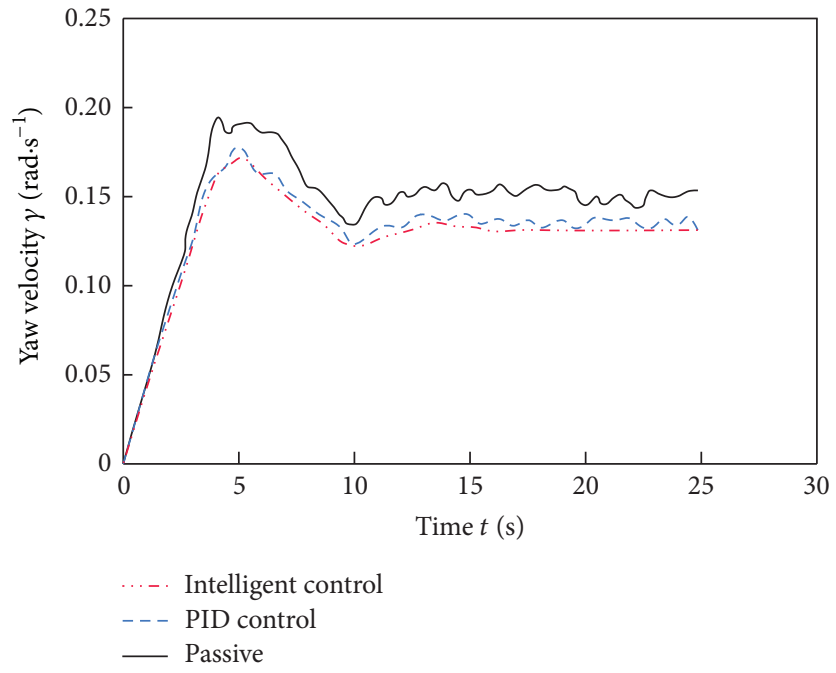

(b) Yaw velocity of vehicle body

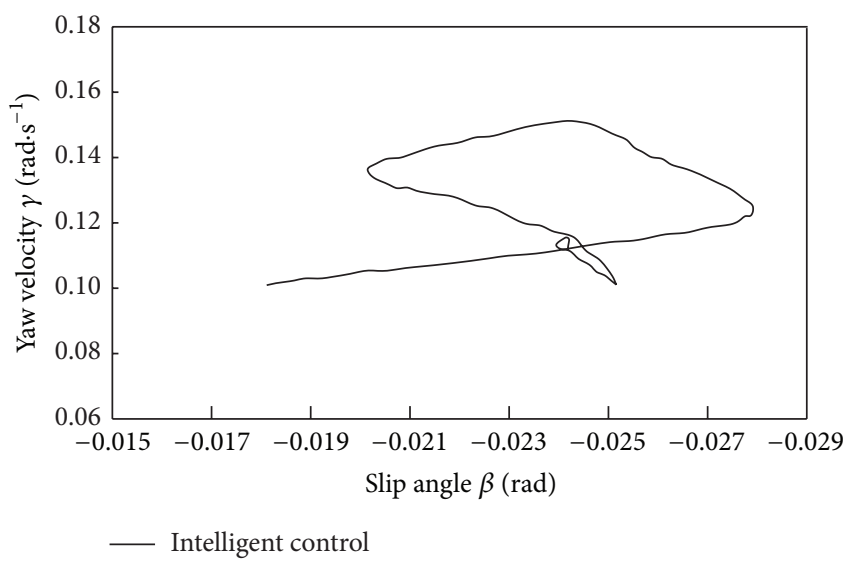

(d) Phase portrait with intelligent control

FIGURE 16: Vehicle results for angle step steering input.

joint simulations for different speeds of a passive and active vehicle, respectively. The test vehicle was equipped with the original passive suspension system and then with the active suspension system with chaos control.

5.2.1. Angle Step Steering Input Operation Conditions. A simulation analysis of the angle step steering input operation conditions can be used to illustrate the improved status of the ASS achieved by stabilizing the handling of the vehicle.

5.2.2. Simulation of the S-Shaped Operation Condition. The road surface was simulated using a vehicle speed of $30 \pm$ $2 \mathrm{~km} / \mathrm{h}$. The primary variables that were measured during the simulation were the steering wheel turning angle, steering wheel torque, and velocity of the vehicle.

\subsubsection{Angle Step Steering Input Operation Conditions on a} Pulse Road. A simulation analysis of the angle step steering input operation conditions on a pulse road can be used to illustrate the improved status achieved by stabilizing the handling and ride comfort of the vehicle. The operation condition used for the simulation consisted of a velocity of $120 \mathrm{~km} / \mathrm{h}(33 \mathrm{~m} / \mathrm{s})$ and front wheel steering angle of $6^{\circ}$. For a dry asphalt road, when the vehicle arrived at the $130 \mathrm{~m}$ point after $4 \mathrm{~s}$, the front and rear axle wheels were excited by the pulse of the road with an amplitude of $5 \mathrm{~cm}$.

5.3. Discussion. Figures $16(\mathrm{a})$ and $16(\mathrm{~b})$ show that the intelligent control applied to ASS + EPS effectively reduced the first resonance of the slip angle and the yaw velocity. It produced better results than a passive suspension system and traditional PID control for ASS+EPS, especially for angle step steering. Although the performance of intelligent control and traditional PID control in the steady state are very close, the former afforded steady operation and produced little noise.

Meanwhile, it can be seen from the phase portraits in Figures 16(c) and 16(d) that the vehicle lateral dynamic runs along elliptic orbits when the intelligent controller is applied but exhibits chaotic behavior when the traditional PID controller is applied. Moreover, the oscillation peaks 


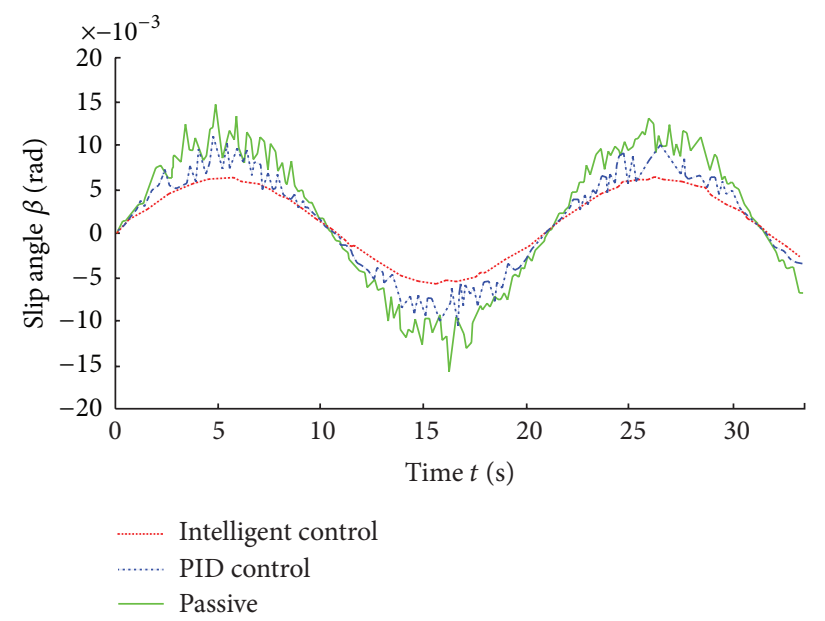

(a) Slip angle of vehicle body

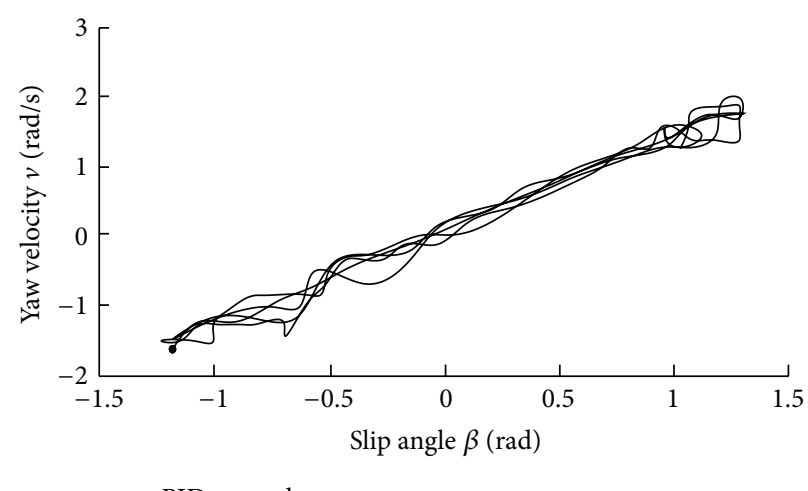

(c) Phase portrait without control

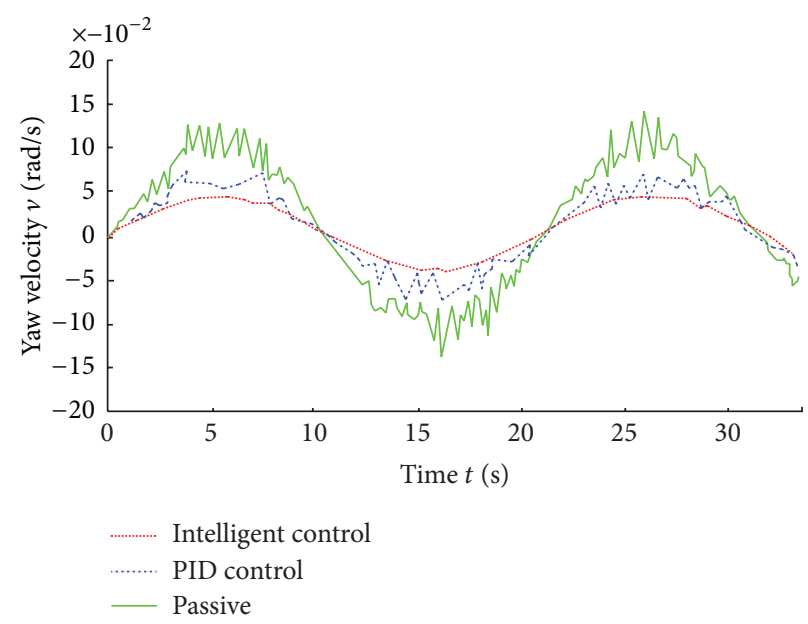

(b) Yaw velocity of vehicle body

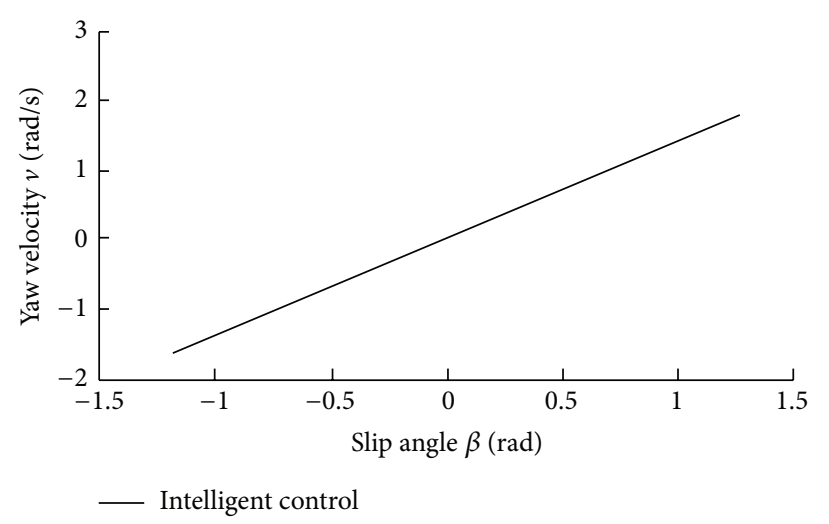

(d) Phase portrait with intelligent control

FIGURE 17: Vehicle results for S-shaped input.

produced by the irregularities are also significantly weakened. This indicates that the proposed control method can be effectively used to suppress chaotic behavior.

Under the S-shaped operation condition, the slip angle and yaw velocity when the intelligent controller is applied are significantly better than the others as shown in Figures 17(a) and 17 (b). The parameters also exhibit greater linearity in the phase portrait for the intelligent controller (Figure 17(d)) but disorder for the PID controller (Figure 17(c)). This also shows that the proposed control method can be effectively used to suppress chaotic behavior.

In Table 5, the intelligent control was proposed to make the Lyapunov exponents of the closed-loop system negative and thereby eliminate chaos from the related system. From these table and figures, it can be concluded that the chaotic oscillators were controlled and the performance of the vehicle and its lateral dynamic were improved.

It can be seen from Figures 18(a) and 18(b) that when the vehicle is unevenly excited by the pulse road, the intelligent control significantly improves the vertical acceleration of the vehicle and the yaw velocity speed amplitude of the vibration. However, the effects of the control in the vertical direction controlled by traditional PID are slightly lower
TABLE 5: Lyapunov exponents for road test.

\begin{tabular}{lccc}
\hline & Measurement points & $\begin{array}{c}\text { Lyapunov } \\
\text { exponents }\end{array}$ \\
\hline \multirow{3}{*}{ Slip angle } & Step input & PID control & 1.89 \\
& & Intelligent control & -0.55 \\
& Snake input & PID control & 2.29 \\
& & Intelligent control & -0.23 \\
\hline \multirow{3}{*}{ Yaw velocity } & \multirow{2}{*}{ Step input } & PID control & 3.18 \\
& & Intelligent control & -0.16 \\
& \multirow{2}{*}{ Snake input } & PID control & 5.16 \\
& & Intelligent control & -1.66 \\
\hline
\end{tabular}

(the acceleration amplitude in the vertical direction is about $\left.1 \mathrm{~m} / \mathrm{s}^{2}\right)$. This is because, in the traditional integrated control system, vertical control and other performance indicators are considered in a single frame, and the amplitude of the controlling force is obtained from the optimal weight acting against the generalized suspension force. The same situation occurs during the pitching movement of the vehicle as shown in Figure 18(c). It should be noted that during the transfer 


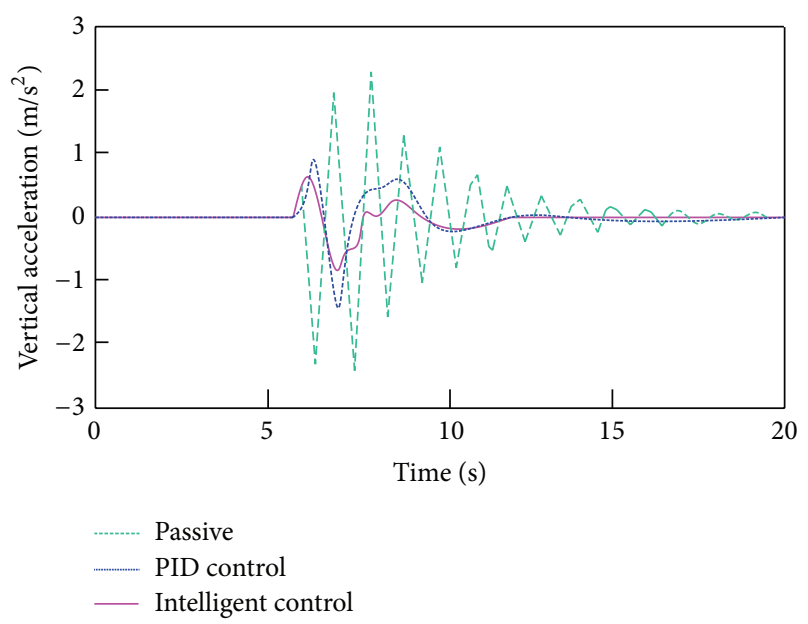

(a)

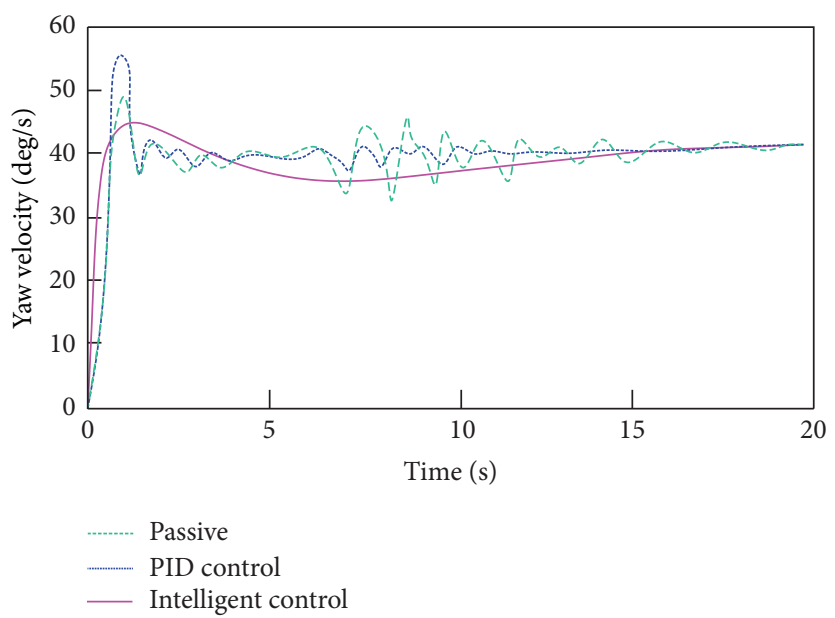

(b)

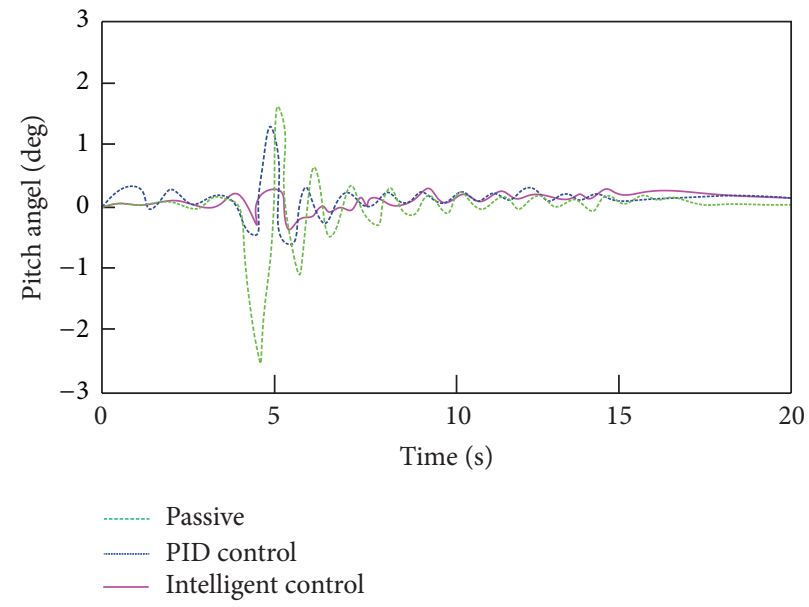

(c)

Figure 18: Results for step-pulse road.

from the step angle to the input, the entire vehicle has a stable roll angle of about $2^{\circ}$ and the process lasts for about $4 \mathrm{~s}$. The uneven excitation of the pulse road significantly affects the roll movement when the vertical load on the wheels changes the yaw and lateral forces, whereas this is not the case for traditional PID control. The negotiation algorithm can compensate for this by continuous negotiation among the different indicators. Moreover, the uneven pulse excitation of the road surface had almost no effect on the manipulation of the vehicle, which also reflects the robustness of the control strategy.

\section{Conclusion}

In this paper, we considered the coupling mechanism of advanced vehicle integration, as well as adaptive neural network of the vehicle wheels. By nonlinear analysis such as the use of bifurcation diagram and the Lyapunov exponent, it was shown that the lateral dynamics of the vehicle was characterized by complicated motions with increasing forward speed. Electric power steering and active suspension system based on intelligent control were used to reduce the nonlinearity, and a negotiation algorithm was designed to manage the interdependences and conflicts among handling stability, driving smoothness, and safety. The results of rapid control prototyping confirmed the feasibility of the proposed control method. By comparing the time response diagrams, phase portraits, and Lyapunov exponents for different operation conditions, we observed that the slip angle and yaw velocity of the lateral dynamics entered a stable domain and the chaotic motions were successfully suppressed. It was also shown that the safety was significantly improved. Under the angle step steering input operation conditions on the pulse road, the proposed intelligent control significantly improved the ride comfort and handling stability. The uneven pulse excitation of the road surface had almost no effect on the manipulation of the vehicle. Future work will focus on optimizing and 
improving the robustness of the control and the information constraints and faults of the integrated vehicle dynamics.

\section{Nomenclature}

\begin{tabular}{|c|c|}
\hline$m, m_{s}:$ & $\begin{array}{l}\text { Qualities of the vehicle and the } \\
\text { suspension, respectively }\end{array}$ \\
\hline$v:$ & Velocity \\
\hline$\beta, \dot{\beta}$ & $\begin{array}{l}\text { Slip angle and slip angular speed, } \\
\text { respectively }\end{array}$ \\
\hline$h_{s}:$ & $\begin{array}{l}\text { Height of the center of gravity of the } \\
\text { vehicle under roll condition }\end{array}$ \\
\hline$\phi, \dot{\phi}, \ddot{\phi}:$ & $\begin{array}{l}\text { Roll angle, roll angular speed, and roll } \\
\text { angular acceleration of the vehicle, } \\
\text { respectively }\end{array}$ \\
\hline$S_{i}:$ & Lateral force on four wheels \\
\hline$I_{\gamma}:$ & Rotary inertia of the vehicle \\
\hline$\gamma, \dot{\gamma}:$ & Yaw rate and yaw acceleration, respectively \\
\hline$L_{f}, l_{r}:$ & $\begin{array}{l}\text { Distances from the front and rear wheels } \\
\text { to the center of the body, respectively }\end{array}$ \\
\hline$z_{s}, \dot{z}_{s}, \ddot{z}_{s}:$ & $\begin{array}{l}\text { Vertical displacement, vertical velocity, } \\
\text { and vertical acceleration of the vehicle } \\
\text { body, respectively }\end{array}$ \\
\hline$F_{2 i}:$ & $\begin{array}{l}\text { Composite force exerted by the } \\
\text { suspension on the vehicle body }\end{array}$ \\
\hline$I_{\theta}, I_{\varphi}:$ & $\begin{array}{l}\text { Pitching rotary inertia and roll rotary } \\
\text { inertia of the vehicle, respectively }\end{array}$ \\
\hline$d:$ & $1 / 2$ of the track \\
\hline$m_{l i}:$ & Unsuspended mass \\
\hline$k_{l i}:$ & Stiffness of the wheels \\
\hline$z_{0 i}:$ & Displacement of the road \\
\hline$z_{1 i}, \dot{z}_{1 i}, \ddot{z}_{1 i}$ & $\begin{array}{l}\text { Vertical displacement, vertical velocity, } \\
\text { and vertical acceleration of the } \\
\text { unsuspended mass }\end{array}$ \\
\hline$k_{a f}, k_{a r}:$ & $\begin{array}{l}\text { Stiffness of the stabilizer bar angle of the } \\
\text { front and rear suspensions, respectively }\end{array}$ \\
\hline$k_{2 i}:$ & Stiffness of the suspension \\
\hline$c_{2 i}:$ & Damping coefficient of the suspension \\
\hline$z_{2 i}, \dot{z}_{2 i}, \ddot{z}_{2 i}:$ & $\begin{array}{l}\text { Vertical displacement, vertical velocity, } \\
\text { and vertical acceleration of the suspended } \\
\text { mass, respectively }\end{array}$ \\
\hline$k_{a f}, k_{a r}:$ & $\begin{array}{l}\text { Stiffness of the stabilizer rods of the front } \\
\text { and rear suspensions, respectively }\end{array}$ \\
\hline$\theta_{j}(k):$ & Input of the jth neuron of the hidden layer \\
\hline$p_{i}(k)$ & Output of the input layer \\
\hline$w_{i j}:$ & $\begin{array}{l}\text { Weight of the connection between the } \\
\text { input and hidden layers }\end{array}$ \\
\hline$\xi_{j}:$ & $\begin{array}{l}\text { Output of the } j \text { th neuron of the hidden } \\
\text { layer }\end{array}$ \\
\hline$v_{j l}:$ & $\begin{array}{l}\text { Weight of the connection between the } \\
\text { hidden and output layers }\end{array}$ \\
\hline$I_{l}:$ & Output of the neuron of the output layer \\
\hline$\alpha_{1}, \alpha_{2}:$ & $\begin{array}{l}\text { Inclination angles of the left-side and } \\
\text { right-side wheels of the front axle, } \\
\text { respectively }\end{array}$ \\
\hline$\alpha_{3}, \alpha_{4}:$ & $\begin{array}{l}\text { Inclination angles of the left-side and } \\
\text { right-side wheels of the rear axle, } \\
\text { respectively }\end{array}$ \\
\hline
\end{tabular}

$\begin{array}{ll}\lambda: & \text { Lyapunov exponent } \\ V_{\mathrm{mrl}}: & \text { Returning control voltage of the motor } \\ \theta_{h}: & \text { Angle of the steering wheel } \\ e_{h}: & \text { Deviation between the target and actual } \\ & \text { steering angles } \\ K_{p}: & \text { Proportionality coefficient } \\ K_{i}: & \text { Integral coefficient } \\ V_{\mathrm{mrh}}: & \text { Returning control voltage of the motor } \\ K_{d}: & \text { Integral coefficient } \\ V_{\mathrm{mr}}: & \text { Aligning control voltage of the motor } \\ e_{d}=I_{d, m, t}-I_{d, m}: & \text { Deviation between the target and actual } \\ & \text { damping currents } \\ I_{d, m, t}: & \text { Armature current for the target damping } \\ e_{d, \mathrm{max}}: & \text { torque } \\ & \text { Maximum deviation between the target } \\ K_{d, \mathrm{PWM}, m}: & \text { and actual damping currents } \\ K_{d, \mathrm{PWM}, \mathrm{max}}: & \text { PWM duty ratio corresponding to } e_{d} \\ & \text { PWM duty ratio corresponding to } e_{d, \text { max }} .\end{array}$

\section{Conflict of Interests}

The authors declare that there is no conflict of interests regarding the publication of this paper.

\section{Acknowledgments}

This project was supported by the National Natural Science Foundation of China (Grant No. 50875112, 51305167), the Ph.D. Programs Foundation of the Ministry of Education of China (Grant no. 20093227110013, 20103227120011), the Jiangsu Municipal Natural Science Foundation (Grant no. BK2010337), and the Natural Science Foundation of Higher Education of Jiangsu (Grant no. 09KJA580001).

\section{References}

[1] H. Glaser, "Electronic stability program ESP," in Audi Press Presentation, pp. 9-13, 1996.

[2] X. Peng, X. Meng, K. Guo, D. Lu, and Y. Xie, "Experimental study of cornering properties of a tire on an icy and a dry pavement," Chinese Journal of Mechanical Engineering, vol. 40, no. 7, pp. 24-28, 2004.

[3] H. B. Pacejka, E. Bakker, and L. Nyborg, "Tyre modeling for use in vehicle dynamics studies," SAE Paper 870421, 1987.

[4] Y. L. Zhou and M. Chen, "Sliding mode control for NSVs with input constraint using neural network and disturbance observer," Mathematical Problems in Engineering, vol. 2013, Article ID 904830, 12 pages, 2013.

[5] B. L. Tian, W. R. Fan, Q. Zong, J. Wang, and F. Wang, "Adaptive high order sliding mode controller design for hypersonic vehicle with flexible body dynamics," Mathematical Problems in Engineering, vol. 2013, Article ID 357685, 11 pages, 2013.

[6] G. Wu and Y. Sheng, "Review on the application of chaos theory in automobile nonlinear system," Chinese Journal of Mechanical Engineering, vol. 46, no. 10, pp. 81-87, 2010.

[7] S. Inagaki, I. Kshiro, and M. Yamamoto, "Analysis on vehicle stability in critical cornering using phase-plane method," in Proceedings of the International Symposium on Advanced Vehicle Control, Tsukuba-shi, Japan, 1994. 
[8] S. Shi, Z. Mao, H. Xiang, and X. Wang, "Nonlinear analysis methods of vehicle cornering stability," Chinese Journal of Mechanical Engineering, vol. 43, no. 10, pp. 77-81, 2007.

[9] X. Yang, Z. Wang, W. Peng, and S. Zhu, "Analysis on lateral dynamic stability and bifurcation of vehicle periodic steering under critical condition," Journal of Highway and Transportation Research and Development, vol. 43, no. 11, pp. 145-149, 2009.

[10] Z. Liu, G. Payre, and P. Bourassa, "Nonlinear oscillations and chaotic motions in a road vehicle system with driver steering control," Nonlinear Dynamics, vol. 9, no. 3, pp. 281-304, 1996.

[11] S.-C. Chang, "On controlling a chaotic vehicle dynamic system by using dither," International Journal of Automotive Technology, vol. 8, no. 4, pp. 467-476, 2007.

[12] E. Ono, S. Hosoe, H. D. Tuan, and S. Doi, "Bifurcation in vehicle dynamics and robust front wheel steering control," IEEE Transactions on Control Systems Technology, vol. 6, no. 3, pp. 412-420, 1998.

[13] S. Chang and H. Lin, "Study on controlling chaos of permanent magnet synchronous motor in electric vehicles," International Journal of Vehicle Design, vol. 58, no. 2, pp. 387-398, 2012.

[14] Z. Zhang, K. T. Chau, and Z. Wang, "Analysis and control of chaos for lateral dynamics of electric vehicles," in Proceedings of the International Conference on Electrical Machines and Systems (ICEMS '11), pp. 1-6, Beijing, China, 2011.

[15] J. D. Lozoya-Santos, R. Morales-Menendez, and R. A. R. Mendoza, "Control of an automotive semi-active suspension," Mathematical Problems in Engineering, vol. 2012, Article ID 218106, 21 pages, 2013.

[16] C. March and T. Shim, "Integrated control of suspension and front steering to enhance vehicle handling," Proceedings of the Institution of Mechanical Engineers D, vol. 221, no. 4, pp. 377391, 2007.

[17] T. Yoshimura and Y. Emoto, "Steering and suspension system of a half car model using fuzzy reasoning and skyhook dampers," International Journal of Vehicle Design, vol. 31, no. 2, pp. 229250, 2003.

[18] A. Alleyne, "A comparison of alternative intervention strategies for unintended roadway departure (URD) control," Vehicle System Dynamics, vol. 27, no. 3, pp. 157-186, 1997.

[19] T. Gordon, M. Howell, and F. Brandao, "Integrated control methodologies for road vehicles," Vehicle System Dynamics, vol. 40, no. 1-3, pp. 157-190, 2003.

[20] Q. Qu and J. Zu, "Variable structure model following control of four-wheel-steering vehicle," International Journal of Vehicle Design, vol. 37, no. 4, pp. 291-310, 2005.

[21] P. Gaspar, I. Szaszi, and J. Bokor, "Design of robust controllers for active vehicle suspension using the mixed $\mu$ synthesis," Vehicle System Dynamics, vol. 40, no. 4, pp. 193-228, 2003.

[22] S.-S. You, H.-S. Choi, H.-S. Kim, T.-W. Lim, and S.-K. Jeong, "Active steering for intelligent vehicles using advanced control synthesis," International Journal of Vehicle Design, vol. 42, no. 3-4, pp. 244-262, 2006.

[23] H. Zhang, Y. Shi, and A. S. Mehr, "On $H_{\infty}$ filtering for discretetime Takagi-sugeno fuzzy systems," IEEE Transactions on Fuzzy Systems, vol. 20, no. 2, pp. 396-401, 2012.

[24] H. Zhang, Y. Shi, and B. Mu, "Optimal $H_{\infty}$-based linearquadratic regulator tracking control for discrete-time Takagisugeno fuzzy fystems with preview actions," Journal of Dynamic Systems, Measurement, and Control, vol. 135, Article ID 044501, pp. 1-5, 2013.
[25] H. Zhang, Y. Shi, and M. Liu, " $\mathrm{H}_{\infty}$ step tracking control for networked discrete-time nonlinear systems with integral and predictive actions," IEEE Transactions on Industrial Informatics, vol. 9, no. 1, pp. 337-345, 2013.

[26] W. Chen, H. Xiao, L. Liu, and J. W. Zu, "Integrated control of automotive electrical power steering and active suspension systems based on random sub-optimal control," International Journal of Vehicle Design, vol. 42, no. 3-4, pp. 370-391, 2006.

[27] Q. Wang, W. Jiang, W. Chen, and J. Zhao, "Simultaneous optimization of mechanical and control parameters for integrated control system of active suspension and electric power steering," Chinese Journal of Mechanical Engineering, vol. 44, no. 8, pp. 6772, 2011. 


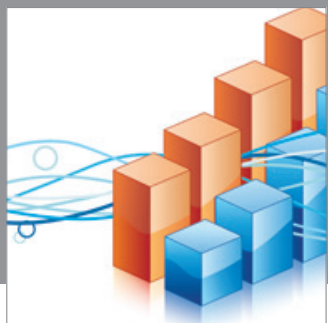

Advances in

Operations Research

mansans

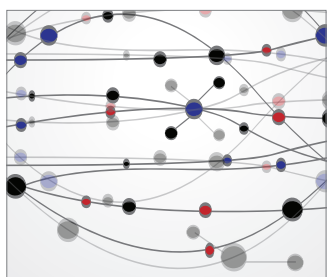

The Scientific World Journal
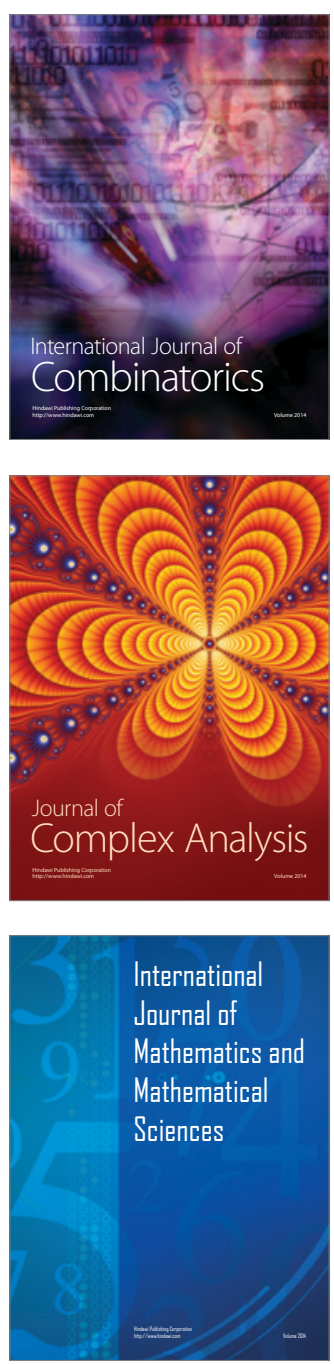
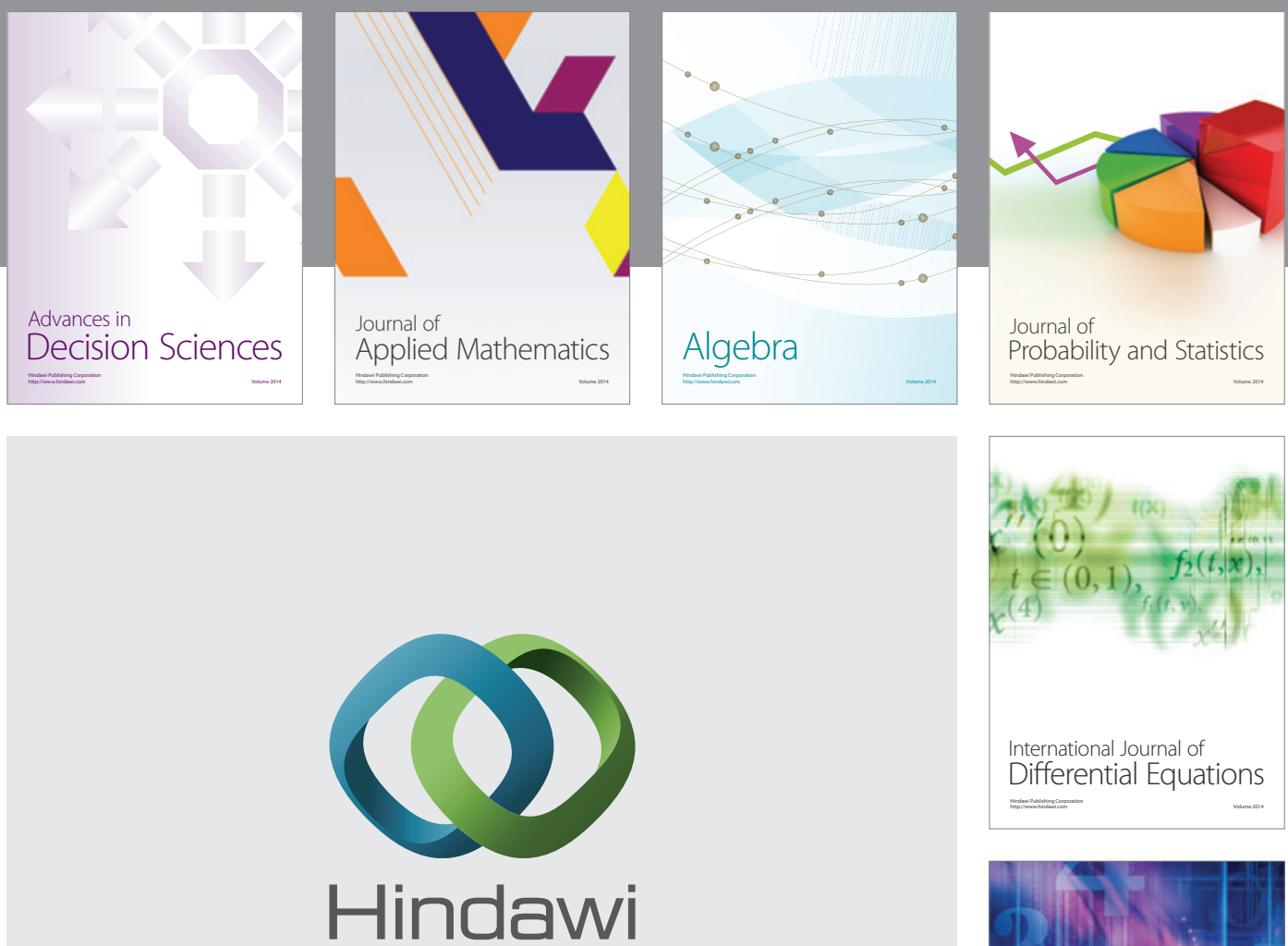

Submit your manuscripts at http://www.hindawi.com
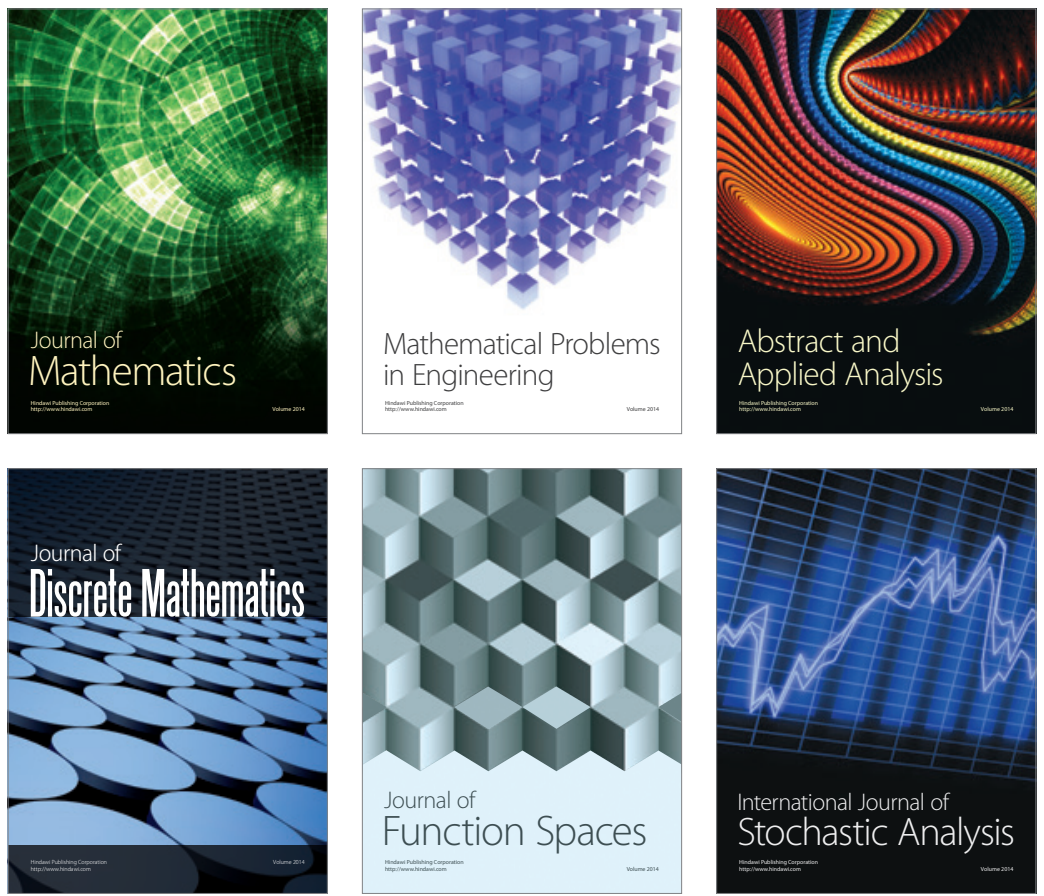

Journal of

Function Spaces

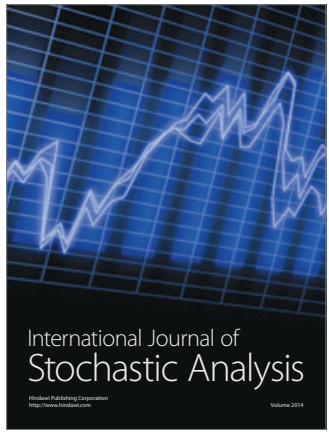

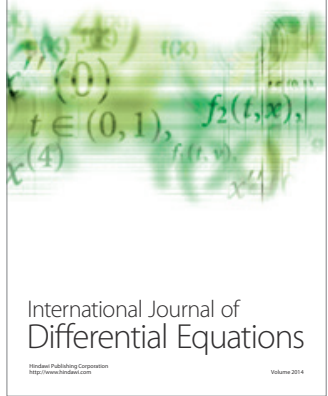
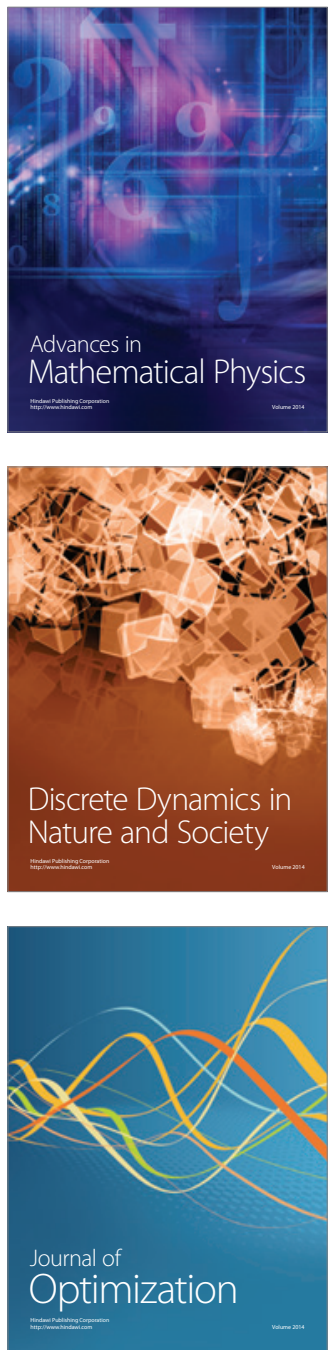